\title{
Segunda revisión de la escala de conducta disocial: el factor del grafiti
}

\author{
José Moral de la Rubia \\ María Elena Pacheco Sánchez
}

\section{Resumen}

El presente estudio tuvo como objetivo: realizar una segunda revisión de la escala de conducta disocial de 27 ítems (ECODI27-R; Moral \& Pacheco, en prensa), generando y seleccionando nuevos indicadores para el factor de grafiti que mostró problemas de consistencia interna. Se definió conducta disocial como un patrón de comportamiento disruptivo en niños y adolescentes quienes de manera persistente transgreden los derechos básicos de los demás a través de agresiones, destrucción de la propiedad, fraudulencia, robo y violaciones graves de normas. La escala se aplicó a una muestra incidental de 245 estudiantes bajacalifornianos de bachiller (114 hombres y 131 mujeres). Se logró conservar 27 ítems perdiendo cuatro (dos de Robo, uno de Travesuras y uno de Pleitos) e incorporando otros cuatro nuevos para el factor de grafiti que alcanzó consistencia interna alta. La escala también conservó sus seis factores correlacionados con un ajuste adecuado a los datos, todos ellos con valores de consistencia interna altos y distribuciones asimétricas negativas, salvo Travesuras que presentó distribución normal. Los hombres reportaron significativamente más rasgos disociales. Los rasgos disociales correlacionaron con mayor número de hermanos y menor ingreso familiar. Así se trata de una escala confiable y válida con mejoras con respecto a las dos versiones anteriores. Se sugiere probar la misma en el ámbito educativo de media superior para establecer sus baremos por medio de percentiles, empleando una muestra probabilística de estudiantes.

\section{Abstract}

The aim of the present study was to conduct a second review of the 27-items Dissocial Behavior Scale (ECODI27-R, Moral \& Pacheco, in press), generating and selecting new indicators for graffiti factor that showed internal consistency problems. Dissocial behavior was defined as a pattern of disruptive behavior in children and adolescents who persistently violate the basic rights of others through aggression, destruction of property, dishonesty, theft and serious violations of rules. The scale was administered to an incidental sample of 245 Baja California high school students (114 men and 131 women). We achieved to retain 27 items losing four (two of Robbery, one of Pranks and one of Disputes) and adding new four items for graffiti factor that reached high internal consistency. The scale also retained its six correlated factors with a proper fit to the data, all of them with high values of internal consistency; negative asymmetric distributions, except Pranks presented normal distribution. Men reported significantly more dissocial traits. Dissocial traits correlated with higher number of siblings and lower family income. Therefore the ECODI-27-R2 scale is a reliable and valid and improvements in compare to the previous two versions. It is suggested testing the scale at the high school level for setting its norms by means of percentiles using a probabilistic sample of students.

Palabras clave: Conducta disocial, adolescencia, validez de un instrumento, grafiti, sexo. 


\section{Introducción}

El trastorno disocial es un patrón de comportamiento persistente y repetitivo, en niños (menores de 11 años) o adolescentes (de 11 a 18 años), que viola los derechos básicos de los demás y normas sociales importantes que, por su edad y capacidad intelectual, el menor debería entender y cumplir. Se manifiesta por agresiones a personas y animales, destrucción de la propiedad, fraudulencia, robo y violaciones graves de normas. Esta conducta ocasiona problemas de adaptación social, acarreando medidas disciplinarias frecuentes e incluso condenas penales (American Psychiatric Association [APA], 2000).

Entre las variables sociodemográficas la conducta disocial se ha asociado con ser hombre (Benjet, Borges, Medina, Blanco et al., 2009; López, Castro, Alcántara, Fernández \& López, 2009; Moral \& Ortiz, 2011), mayor número de hermanos y ocupar los últimos órdenes de nacimiento (Bègue \& Roché, 2005; Lalumière, Harris, Quinsey \& Rice, 2004), desintegración familiar (Diamond \& Josephson, 2005; Musitu, 2001), estatus socio-económico bajo (Santrock, 2008; Silva, 2003), presencia de pandillas en la colonia (Mobilli \& Rojas, 2006) y marginalidad del entorno social (Barak, 2009; Cava \& Musitu, 2000). Asimismo se señala que conducta antisocial se atenúa con la edad (Benjet, Borges \& Medina, 2010; Hare, 2003; Millon, 2004), aunque el efecto probablemente sea más sutil en la etapa adolescente de los 14 a 18 años (Eisenberg, 2005; Miller, Malone, \& Dodge, 2010).

En México Moral y Pacheco (2010a) desarrollaron la Escala de Conducta Disocial de 27 reactivos (ECODI-27). Los autores partieron de un trabajo con expertos desde la definición del trastorno en la cuarta edición del Manual Diagnóstico y Estadístico de Trastornos Mentales (DSM-IV-TR; APA, 2000), un trabajo exploratorio de conductas disruptivas en los planteles de bachiller con los docentes y una evaluación de la comprensibilidad de los reactivos entre los alumnos de bachiller. La escala generada presentó una estructura de seis factores correlacionados: Robo y vandalismo ( $\alpha=.88$ con 8 ítems), Travesuras ( $\alpha=.77$ con 6 ítems), Abandono escolar ( $\alpha=.83$ con dos ítems), Pleitos y armas ( $\alpha=.78$ con 5 ítems), Grafiti $(\alpha=.72$ con 3 ítems) y Conducta oposicionista desafiante ( $\alpha=.69$ con tres ítems). Este modelo factorial mostró un ajuste a los datos de bueno $(R M S S R=.05, R M S E A=.04, A G F I=.91, N F I$ $=.90)$ a adecuado $\left(\chi^{2} / g l=2.56, \mathrm{GFI}=.93, \mathrm{NNFI}\right.$ $=.93, C F I=.94)$ por Máxima Verosimilitud. Además, al evaluar la validez de contenido, los autores indicaron que los 27 ítems cubrían de forma adecuada el campo semántico del concepto, salvo la crueldad con los animales. Debe señalarse que no se logró definir dicho factor a pesar de contar con ítems específicos para el mismo. Los 27 ítems seleccionados tuvieron una consistencia interna alta $(\alpha=.91)$, y la puntuación total, obtenida por suma simple de los mismos, resultó estable a las cuatro semanas $(r=.78)$ (Moral \& Pacheco, 2010a).

La distribución de la puntuación total del ECODI27 fue asimétrica negativa en estudiantes, con diferencia por sexos, pero la distribución fue normal en varones infractores. La puntuación total del ECODI27 presentó un sesgo significativo de deseabilidad social, medida por la escala de sinceridad del Cuestionario de Personalidad de Eysenck (EPI; Eysenck \& Eysenck, 1997), siendo el efecto muy limitado $(r=-.11, p<.01)$. Se propuso como punto de corte una puntuación de 85 o menor, la cual permite diferenciar al $9 \%$ de estudiantes de bachillerato ( $4 \%$ de las mujeres y $14 \%$ de los hombres) y $50 \%$ de infractores varones (Pacheco \& Moral, 2010), ajustándose a las estimaciones del trastorno por la American Psychiatric Association (APA, 2000), Instituto Mexicano de Psiquiatría (Benjet, Borges, Medina, Blanco et al., 2009; Benjet, Borges, Medina, Méndez et al., 2009) y estudios en estudiantes mexicanos (Juárez, Villatoro, Gutiérrez, Fleiz \& Medina., 2005). 
Moral y Ortiz (2011), en una muestra probabilística, en dos colonias de altos índices de pandillas y delincuencia, con este punto de corte hallan un tercio de adolescente como casos de conducta disocial. El porcentaje de casos en mujeres fue de $18 \%$ frente al $45 \%$ en hombres, lo que se ajustó a las expectativas del estudio, validándose así el punto de corte.

Moral \& Pacheco (2010b) validaron, por análisis factorial confirmatorio por el método multigrupo, el modelo de seis factores correlacionados para los 27 ítems del ECODI27 en tres muestras: estudiantes mujeres, estudiantes varones e infractores varones. La estructura factorial mostró un ajuste de bueno a adecuado. Asimismo, Moral (2010) también validó dicho modelo en adolescentes que residen en colonias populares. En ambos estudios se sugería ampliar el factor de Abandono escolar al quedar integrado sólo por dos ítems, eliminado un tercero, lo que es un número muy reducido, cuando se recomienda un mínimo de tres (Kline, 2010). Esta sugerencia toma más peso al ser un factor importante de conductas disruptivas en el ámbito urbano y escolar (Martins-da Cruz \& Costa, 2008; Yogan \& Johson, 2006) y necesario para la validez de contenido de la escala (APA, 2000); y al considerar la consistencia interna alta de los dos ítems que se retienen en el factor.

Moral y Pacheco (en prensa) crearon nuevos ítems para el factor de Abandono escolar. En una muestra incidental de 389 bachilleres de Mexicali (56\% mujeres y $44 \%$ hombres) aplicaron el ECODI27 junto con nuevos 17 ítems. Para lograr la estructura de seis factores correlacionados originales se eliminaron cuatro ítems (dos del factor de travesuras y dos del factor de robo) y se añadieron cuatro al factor de abandono escolar. El ajuste por mínimos cuadrados generalizados fue de bueno ( $F D=$ 1.32, $\chi 2 / g l=1.66, R S M E A=.04, P N C P=0.52)$ a adecuado ( $R M S S R=.08, G F I=.90$ y $A G F I=$ .88). Todos los factores lograron valores altos de consistencia interna: $\alpha=.75$ para los cinco ítems de pleitos y armas, $\alpha=.74$ para los seis ítems de robo y vandalismo y los tres ítems de conducta oposicionista desafiante y $\alpha=.72$ para los cinco ítems de abandono escolar y los cuatro ítems de travesuras, salvo los tres ítems del factor de grafiti $(\alpha=.58)$. Este último factor alcanzaba un valor de consistencia interna aceptable ( $\alpha$ $=.61$ ), si se eliminaba el ítem 14 "el grafiti es un arte que todos los jóvenes deben expresar." Debido a la debilidad del factor de grafiti y su importancia para la validez de contenido, se sugería generar nuevos ítems para el mismo y desarrollar así una segunda revisión de la escala. Además, con un mayor número de ítems, si éstos fueran buenos indicadores del grafitismo como actividad disruptiva, se alcanzaría fácilmente consistencia interna alta, lo que se observó con sólo dos ítems en los dos estudios del ECODI antes mencionados, cuando resultó adecuada en este tercero.

Considerando las buenas propiedades de consistencia interna, estabilidad temporal, reproducción factorial y validez de constructo que presenta esta escala creada en México, se desea continuar con su revisión, tras hallarse nuevas fallas en la primera realizada. Así, el presente estudio tiene como objetivos: a) realizar una segunda revisión de la escala de conducta disocial de 27 ítems (ECODI27-R; Moral \& Pacheco, en prensa), generando y seleccionando nuevos indicadores para el factor de Grafiti que mostró problemas de consistencia interna; se pretende conservar la estructura de seis factores correlacionados e incluso el mismo número de ítems, esto es, 27 ; b) describir la distribución de la escala y los factores; y c) estudiar su relación con las variables sociodemográficas de sexo, edad, familiar con el que vive el adolescente, número de hermanos, orden de nacimiento y ocupación de los padres, las cuales se han señalado como correlatos significativos en la literatura y permiten así evaluar la validez de la escala.

Desde los antecedentes revisados se espera que las distribuciones del puntaje total 
y los factores sean asimétricas negativas entre estudiantes de media superior y que las mujeres muestren significativamente menores rasgos de conducta disocial que los hombres (mayor promedio) (Moral \& Pacheco, 2010a; Moral \& Pacheco, en prensa); asimismo, se pronostican mayores rasgos de conducta disocial a menor edad en la etapa adolescente de los participantes (de 14 a 18 años), aunque con una asociación muy débil (Eisenberg, 2005; Miller et al., 2010), cuando el adolescente vive sólo con uno de los padres, a mayor número de hermanos, a un orden más tardío de nacimiento y ocupación no cualificada del padre (Barak, 2009; Bègue, \& Roché, 2005; Silva, 2003).

\section{Método}

\section{Participantes}

La muestra incidental de 245 participantes voluntarios quedó integrada por 114 hombres $(46.5 \%)$ y 131 mujeres $(53.5 \%)$, siendo estadísticamente equivalente la frecuencia de ambos sexos (prueba binomial: $p=.31$ ). Todos ellos eran estudiantes de una preparatoria pública de la ciudad de Mexicali, Baja California. La media de edad fue de 15.21 años (DE = $0.62)$ con una mínima de 14 años y máxima de 18. El $71 \%$ (174 de 244) dijo vivir con ambos padres, $25 \%$ (61 de 244 ) sólo con la madre, $3 \%$ (7 de 244) sólo con el padre y 1\% (2 de 244) estaban emancipados. La mediana y moda del número de hermanos fue de 2 , variando de 0 a más de 4.

En relación con la ocupación del padre, 59\% (115 de 195) de los participantes señalaron que sus padres estaban contratados para trabajos que no requerían estudios o precisaban de un máximo de secundaria, 11\% (22 de 195) para trabajos que requerían preparatoria técnica y $12 \%$ (24 de 195) para trabajos que demandaban estudios superiores. El 17\% (34 de 195) restante de los padres se dedicaba al comercio.

En relación con la ocupación de la madre, 66\% (155 de 234) de los participantes dijeron que sus madres se dedicaban exclusivamente a su hogar, 15\% (36 de 234) informaron que estaban contratadas para un trabajo que no requería estudios o un máximo de secundaria, $8 \%$ (19 de 234) para un trabajo que requería preparatoria técnica y $7 \%$ (17 de 234) para un trabajo que demandaba estudios universitarios. El 3\% (7 de 234) restante de las madres se dedicaba al comercio (véase tabla 1).

Tabla 1

Datos sociodemográficos

\begin{tabular}{|c|c|c|c|}
\hline Variable & Valores & $f$ & $\%$ \\
\hline \multirow{3}{*}{ Sexo } & Hombre & 114 & 46.5 \\
\hline & Mujer & 131 & 53.5 \\
\hline & Total & 245 & 100 \\
\hline \multirow{6}{*}{ Edad } & 14 & 11 & 5 \\
\hline & 15 & 163 & 74.4 \\
\hline & 16 & 34 & 15.5 \\
\hline & 17 & 10 & 4.6 \\
\hline & 18 & 1 & 0.5 \\
\hline & Total & 219 & 100 \\
\hline \multirow{5}{*}{$\begin{array}{l}\text { Familiar } \\
\text { con quien } \\
\text { vive } \\
\text { el adolescente }\end{array}$} & Ambos padres & 174 & 71.3 \\
\hline & Madre sola & 61 & 25 \\
\hline & Padre solo & 7 & 2.9 \\
\hline & Emancipado & 2 & 0.8 \\
\hline & Total & 244 & 100 \\
\hline \multirow{6}{*}{$\begin{array}{l}\text { Número } \\
\text { de } \\
\text { hermanos }\end{array}$} & 0 & 8 & 3.3 \\
\hline & 1 & 35 & 14.5 \\
\hline & 2 & 127 & 52.7 \\
\hline & 3 & 12 & 5.0 \\
\hline & 4 o más & 59 & 24.5 \\
\hline & Total & 241 & 100 \\
\hline \multirow{5}{*}{$\begin{array}{l}\text { Ocupación } \\
\text { del } \\
\text { padre }\end{array}$} & Trabajador manual & 115 & 59.0 \\
\hline & Técnico & 22 & 11.3 \\
\hline & Comercio & 34 & 17.4 \\
\hline & Profesionista & 24 & 12.3 \\
\hline & Total & 195 & 100.0 \\
\hline \multirow{6}{*}{$\begin{array}{l}\text { Ocupación } \\
\text { de la } \\
\text { madre }\end{array}$} & Ama de casa & 155 & 66.2 \\
\hline & $\begin{array}{c}\text { Trabajadora } \\
\text { manual }\end{array}$ & 36 & 15.4 \\
\hline & Técnica & 19 & 8.1 \\
\hline & Comercio & 7 & 3.0 \\
\hline & Profesionista & 17 & 7.3 \\
\hline & Total & 234 & 100 \\
\hline
\end{tabular}




\section{Instrumento de medida}

Escala de conducta disocial. Se emplea la versión revisada por Moral y Pacheco (en prensa) de 27 ítems, en la que el factor de abandono escolar está integrado por seis ítems. En este estudio se añaden ocho ítems para evaluar conductas y actitudes relacionadas con el grafiti con el fin de seleccionar nuevos indicadores para este factor. Los 35 ítems aplicados tienen un formato tipo Likert con un rango de respuesta de cinco puntos cada uno (de 1 "totalmente de acuerdo" a 5 "totalmente en desacuerdo"). Todos están redactados en el mismo sentido, reflejando rasgos disociales. Las puntuaciones en la escala y sus factores se obtienen por suma simple de ítems. A menor puntuación, mayor presencia de conductas disociales, al reflejar mayor acuerdo con los rasgos disociales. Véase anexo.

\section{Procedimiento}

Para generar los nuevos ítems del factor de grafiti se partió de la técnica de grupo focal. A veinte alumnos de primer semestre de la Universidad Autónoma de Baja California (UABC) de la Facultad de Diseño Gráfico se les invitó a participar en un grupo para discutir y comentar sobre el grafiti en la ciudad. Seis de ellos se identificaron como grafiteros con más de un año en esta práctica y el resto reconoció haber hecho grafitis en alguna ocasión o tener conocidos que lo practicaban. La edad promedio fue de 18 años, variando de 17 a 20. El 60\% (12 de 20) procedía de colonias de estatus socioeconómico bajo y $40 \%$ (8 de 20) de estatus medio. El grupo duraba dos horas y la sesión fue grabada con cámara de video. Se pidió a los participantes autorización para filmarlos, sólo uno de ellos se negó y no se le incluyó en el estudio. La sesión de grupo se llevó a cabo en un aula de la Facultad de Diseño Gráfico.

A un grupo de expertos se les invitó a escuchar y ver la grabación para que analizaran el contenido de la misma y así elaborar los ítems. El grupo de expertos estuvo integrado por seis orientadores educativos de la UABC con más de 15 años de trabajo con adolescentes y jóvenes.

Los ítems redactados se agruparon por su equivalencia semántica y los investigadores de este estudio seleccionaron aquéllos que presentaban una estructura, sintaxis, y contenido más adecuados para el uso del lenguaje de la población de estudiantes de media superior y para los objetivos del completar el factor de grafiti.

La escala ECODI27 junto con los ítems adicionales y las preguntas sociodemográficas se aplicaron en los salones de clases tras pedir permiso a las autoridades del plantel, maestros y solicitar el consentimiento informado de los participantes, explicando en la primera hoja el propósito del estudio y sus responsables. La respuesta al cuestionario era anónima y se garantizaba la confidencialidad de los resultados individuales, ajustándonos a las normas éticas de la Asociación Psicológica Americana (APA, 2002) y la Sociedad Mexicana de Psicología (2007). La muestra se levantó de agosto a septiembre de 2011.

\section{Análisis estadísticos}

La consistencia interna se estima por el coeficiente alfa de Cronbach $(\alpha)$. Se consideran valores altos aquéllos $\geq .70$, adecuados $\geq .60$ y bajos < .60 (Cronbach \& Shavelson, 2004). El ajuste de la distribución a una curva normal se contrasta por la prueba de Kolmogorov-Smirnov $\left(Z_{K-S}\right)$.

La estructura dimensional se determina primero por análisis factorial exploratorio. Se emplea como método de extracción: Componentes Principales, y como método de rotación: Oblimín. Se escogen como indicadores de cada componente aquellos ítems cuyas cargas factoriales más altas y mayores o iguales a .30 aparecen en el componente dentro de la matriz de patrones. 
En segundo lugar se contrasta el modelo de seis factores correlacionados por análisis factorial confirmatorio. Se usa Mínimos Cuadrados Generalizados (GLS) como método para estimar la función de discrepancia, parámetros e índices de ajuste. Al calcular el modelo no se estiman medias ni interceptos y las covarianzas de entrada son insesgadas. Las estimaciones de parámetros se proporcionan estandarizadas. Se consideran siete índices de ajuste: tres básicos (función de discrepancia $[F D]$, chi-cuadrado [ $\chi 2]$ y cociente entre chicuadrado y sus grados de libertad $[\chi 2 / g /])$; dos poblacionales de no centralidad (parámetro de no centralidad poblacional $[P N C P]$ y residuo cuadrático medio de aproximación [RMSEA] de Steiger-Lind); además, dos índices comparativos (índice de bondad de ajuste [GFl] de Jöreskog y Sörbom y su modalidad corregida $[A G F I])$. Se estipulan como valores de buen ajuste: $p$ de $\chi 2>$ $.05, F D$ y $\chi 2 / g I<2, P N C P<1, R M S E A<.05$, GFI $>.95$ y $A G F I>.90$; y como valores adecuados: $p$ de $\chi 2>.01, F D$ y $\chi 2 / g l<3, P N C P<2, R M S E A$ $<.08, \mathrm{GFI}>.85$ y AGFI > .80 (Moral, 2006). Estos modelos también son contrastados por el método multigrupo entre hombres y mujeres sin introducir restricciones; nuevamente no se calculan medias ni interceptos y las covarianzas de entrada son insesgadas.

Debido a la asimetría y falta de normalidad de las distribuciones del puntaje total y los factores de la escala, las diferencias de tendencia central entre los sexos se contrastan por la prueba $U$ de Mann-Whitney, y entre los grupos de ocupación de la madre, del padre y familiar con el que vive el adolescente por la prueba de Kruskal-Wallis. La correlación con la edad, número de hermanos y orden de nacimiento por el coeficiente rho de Spearman $\left(r_{s}\right)$.

En las pruebas de contraste se rechaza la hipótesis nula con un valor de $p \leq .05$. Se sustituyen los casos perdidos por la media de la variable. El número máximo de sustituciones fue de cuatro por variable. Los cálculos estadísticos se realizan con SPSS16 y AMOS7.

\section{Resultados}

\section{Estructura factorial y consistencia interna de los factores}

Por el criterio de Kaiser (autovalores iniciales mayores a 1) se definen nueve componentes que explican el $62.47 \%$ de la varianza total. Por el criterio de Cattell (punto de inflexión de la curva de sedimentación) se pueden definir seis componentes que coinciden con el número esperado. Con seis componentes se explica el $52.63 \%$ de la varianza total. Para una interpretación más clara de la solución, la matriz de componentes se rota por el método Oblimin (véase Tabla 2).

El primer componente está definido por diez ítems que corresponden a contenidos relacionados con los grafitis $(25,26,27,28,30$, $31,32,33,34$ y 35). La consistencia interna es alta $(\alpha=.81)$ y no mejora con la eliminación de ningún ítem. Le faltaría el ítem 29 "el grafiti debe ser reconocido como una actividad artística" que satura en el factor de abandono escolar. Su inclusión no mejora ni disminuye la consistencia interna.

El segundo componente corresponde a los seis ítems de abandono escolar $(6,7,8,9,10$ y 11). También satura con carga alta $(I=.40)$ el ítem 29 que correspondería al componente de grafiti, como antes se señaló. La consistencia interna de los seis ítems de abandono escolar es alta $(\alpha=.81)$ y disminuye considerablemente si se le añade el ítem 29 de grafiti $(\alpha=.68)$, por lo que sería mejor eliminarlo.

El tercer componente corresponde a los tres ítems de conducta oposicionista desafiante (18, 19 y 20). La consistencia interna es alta $(\alpha=.76)$.

El cuarto componente corresponde a cuatro ítems de pleitos (1, 2, 3 y 4$)$ se le añade uno de robo (16) y le falta uno relacionado con portar armas (5). La consistencia interna de los cuatro ítems de pleitos es alta $(\alpha=.78)$. Si se añade el ítem de robo desciende ligeramente, 
al igual que si se añade el ítem cinco que se esperaba que saturara alto en este factor $(\alpha=$ .75, en ambos casos). Por lo tanto, sería mejor denominarlo simplemente como pleitos cuando originalmente se nominó pleitos y armas.

El quinto componente corresponde a cuatro ítems de robo $(12,13,14$ y 15). Le faltan el ítem 16 relacionado con planear robos que satura alto en el componente de pleitos y el ítem 17 relacionado con vandalismo que no satura alto en ninguno de los seis factores. La consistencia interna de los cuatro ítems de robo es alta $(\alpha=.75)$. Si se añaden los dos ítems faltantes disminuye la consistencia interna $(\alpha=.72)$ y ésta aumenta con la eliminación de cualquiera de los dos. Por lo tanto, sería conveniente eliminar los ítems 16 y 17.

El sexto componente corresponde a los cuatro ítems de travesuras $(21,22,23$ y 24). Se le añade el ítem cinco relacionado con portar armas. La consistencia interna de los cuatro ítems de travesuras es alta $(\alpha=.72)$ y disminuye si se añade el ítem cinco $(\alpha=.66)$. También sería conveniente eliminar el ítem 5.

Tabla 2

Matriz de patrones con seis factores y 35 ítems

\begin{tabular}{|c|c|c|c|c|c|c|}
\hline \multirow{2}{*}{ Ítems } & \multicolumn{6}{|c|}{ Componentes } \\
\hline & $\mathrm{C} 1$ & $\mathrm{C} 2$ & C3 & $\mathrm{C} 4$ & C5 & C6 \\
\hline $\begin{array}{l}\text { 32. Te sientes más confiado cuando grafiteas en grupo que cuando estás } \\
\text { solo. }\end{array}$ & .76 & .10 & -.12 & .01 & .01 & -.04 \\
\hline 30. Cuando grafiteas, por lo general, buscas espacios públicos. & .74 & -.03 & .21 & -.06 & .00 & .05 \\
\hline 35. Me gustan las bardas recién pintadas para marcar mi firma (grafiti). & .70 & -.14 & .02 & -.02 & -.12 & .00 \\
\hline $\begin{array}{l}\text { 33. El tener permiso de las autoridades para grafitear hace que se pierda la } \\
\text { emoción. }\end{array}$ & .62 & -.06 & -.12 & .02 & .03 & .10 \\
\hline 34. Me gusta que reconozcan mi firma en grafiti. & .59 & .25 & .00 & .24 & -.12 & .11 \\
\hline 28. Entre mayor riesgo se presente cuando grafiteas, la emoción aumenta. & .58 & -.15 & .04 & -.02 & -.03 & -.12 \\
\hline 26. Me emociona subir a edificios muy altos para grafitear. & .54 & -.25 & .04 & .03 & .07 & .03 \\
\hline 25. Alguna vez he participado en grafiti con mis amigos. & .46 & -.14 & .09 & .03 & .06 & -.16 \\
\hline 31. Te irrita que grafiteen encima de alguna creación tuya. & .45 & .07 & .27 & .02 & .07 & -.07 \\
\hline 27. El grafiti es un arte que todos los jóvenes deben expresar. & .38 & .34 & -.24 & .13 & -.37 & -.25 \\
\hline $\begin{array}{l}\text { 17. He estado involucrado en actividades que dañan la propiedad } \\
\text { ajena como: autos, casas, edificios públicos y objetos. }\end{array}$ & .23 & -.11 & .21 & .14 & -.20 & -.03 \\
\hline 7. La escuela no es para mí. & .11 & -.75 & -.07 & .12 & -.11 & -.05 \\
\hline 8. Quiero abandonar la escuela. & .01 & -.75 & -.14 & .17 & -.12 & -.03 \\
\hline 10. La escuela es una pérdida de tiempo. & .02 & -.62 & .09 & -.03 & -.32 & .06 \\
\hline $\begin{array}{l}\text { 6. Por más esfuerzo que hago por terminar la escuela creo que no lo } \\
\text { lograré. }\end{array}$ & .15 & -.61 & .16 & .08 & -.01 & .00 \\
\hline 9. He pensado dejar la escuela. & .16 & -.59 & -.10 & -.01 & -.03 & -.15 \\
\hline $\begin{array}{l}\text { 11. De reprobar dos o tres asignaturas al final del semestre, será mejor } \\
\text { dejar la escuela y buscar trabajo. }\end{array}$ & .05 & -.53 & -.15 & .11 & -.16 & -.21 \\
\hline 29. El grafiti debe ser reconocido como una actividad artística. & .26 & .40 & -.02 & .19 & -.34 & -.20 \\
\hline $\begin{array}{l}\text { 19. Cuando creo que los adultos no tienen la razón los desafío a que me } \\
\text { demuestren lo contrario. }\end{array}$ & -.05 & .03 & .85 & .08 & -.01 & -.05 \\
\hline 18. No me dejo de los adultos cuando siento que no tienen la razón. & -.07 & .02 & .74 & -.02 & -.10 & -.11 \\
\hline 20. Trato de desafiar a los profesores que han sido injustos conmigo. & .22 & .11 & .67 & .01 & .05 & -.08 \\
\hline 2. Frecuentemente he tenido que pelear para defenderme. & -.04 & -.08 & .11 & .82 & .18 & .02 \\
\hline
\end{tabular}


1. Cuando me agreden respondo inmediatamente a golpes.

3. Me gusta participar en pleitos.

4. Cuando me ofenden respondo inmediatamente y

si es necesario hasta con golpes.

16. Me gusta planear robos.

13. Alguna vez he robado sin que nadie se dé cuenta.

14. He participado en pequeños robos sólo por experimentar qué se siente.

12. He participado en robos.

15. Es fácil tomar cosas ajenas porque las personas son descuidadas con sus objetos.

21. Es divertido hacer ruido y alboroto en un lugar cuando todo está en silencio.

22. Cuando estoy aburrido en clase, inicio algún tipo de movimiento para divertirme.

23. Siento que a veces no puedo controlar mi impulso de hacer alguna travesura.

24. Es divertido observar cuando los compañeros se pelean.

5. Es necesario andar armado porque estás expuesto a que en cualquier momento te puedan agredir.

\begin{tabular}{llllll}
-.03 & .04 & .04 & .80 & .04 & -.05 \\
.01 & -.13 & -.07 & .71 & .08 & -.10 \\
.07 & .05 & -.06 & .71 & .02 & -.10 \\
-.07 & -.11 & .05 & .44 & -.32 & .31 \\
-.10 & -.02 & .07 & -.12 & -.87 & -.07 \\
.01 & -.04 & .03 & -.02 & -.76 & -.07 \\
.07 & -.25 & .00 & -.07 & -.70 & .09 \\
-.03 & -.08 & .02 & -.01 & -.61 & -.05 \\
.02 & -.15 & .06 & -.01 & .05 & -.72 \\
.00 & -.01 & .16 & .07 & -.10 & -.71 \\
& & & & & \\
-.06 & -.01 & .17 & .13 & -.15 & -.63 \\
.05 & -.09 & .02 & .25 & -.20 & -.42 \\
.14 & -.02 & .19 & .29 & -.17 & .31 \\
\hline
\end{tabular}

Método de extracción: Componentes principales. Método de rotación: Oblimin. La rotación conversión en 13 iteraciones. Componentes: C1: Grafiti, C2: Abandono escolar, C3: Conducta oposicionista desafiante, C4: Pleitos, C5: Robos y C6: Travesuras.

Con base en las saturaciones y cálculos de consistencia interna se eliminan cuatro ítems: $5,16,17$ y 29. Al extraer los seis componentes entre los 31 ítems restantes se explica el $56.02 \%$ de la varianza total y todos los ítems saturan alto en el factor esperado (véase tabla 3).

Tabla 3

Matriz de patrones con seis factores y 31 ítems

\begin{tabular}{|c|c|c|c|c|c|c|}
\hline \multirow{2}{*}{ Ítems } & \multicolumn{6}{|c|}{ Componentes } \\
\hline & 1 & 2 & 3 & 4 & 5 & 6 \\
\hline $\begin{array}{l}\text { 32. Te sientes más confiado cuando grafiteas en grupo que cuando estás } \\
\text { solo. }\end{array}$ & .76 & .10 & -.12 & .01 & .01 & -.08 \\
\hline 30. Cuando grafiteas, por lo general, buscas espacios públicos. & .71 & -.04 & .24 & .01 & -.05 & .13 \\
\hline 35. Me gustan las bardas recién pintadas para marcar mi firma (grafiti). & .69 & -.12 & .01 & .01 & -.15 & -.00 \\
\hline $\begin{array}{l}\text { 33. El tener permiso de las autoridades para grafitear hace } \\
\text { que se pierda la emoción. }\end{array}$ & .62 & -.08 & -.12 & .00 & .05 & .07 \\
\hline 34. Me gusta que reconozcan mi firma en grafiti. & .61 & .23 & .03 & .24 & -.14 & .10 \\
\hline $\begin{array}{l}\text { 28. Entre mayor riesgo se presente cuando grafiteas, } \\
\text { la emoción aumenta. }\end{array}$ & .57 & -.15 & .02 & -.03 & -.02 & -.16 \\
\hline 26. Me emociona subir a edificios muy altos para grafitear. & .51 & -.25 & .05 & .05 & .04 & .08 \\
\hline 31. Te irrita que grafiteen encima de alguna creación tuya. & .46 & .02 & .26 & -.04 & .14 & -.17 \\
\hline 25. Alguna vez he participado en grafiti con mis amigos. & .43 & -.11 & .09 & .08 & .00 & -.10 \\
\hline 27. El grafiti es un arte que todos los jóvenes deben expresar. & .40 & .27 & -.21 & .11 & -.30 & -.26 \\
\hline
\end{tabular}

\section{PSICUMEX}


7. La escuela no es para mí.

8. Quiero abandonar la escuela.

6. Por más esfuerzo que hago por terminar la escuela creo que no lo lograré.

9. He pensado dejar la escuela.

10. La escuela es una pérdida de tiempo.

11. De reprobar dos o tres asignaturas al final del semestre, será mejor dejar la escuela y buscar trabajo.

19. Cuando creo que los adultos no tienen la razón los desafío a que me demuestren lo contrario.

18. No me dejo de los adultos cuando siento que no tienen la razón.

20. Trato de desafiar a los profesores que han sido injustos conmigo.

1. Cuando me agreden respondo inmediatamente a golpes.

2. Frecuentemente he tenido que pelear para defenderme.

4. Cuando me ofenden respondo inmediatamente y si es necesario hasta con golpes.

3. Me gusta participar en pleitos.

13. Alguna vez he robado sin que nadie se dé cuenta.

14. He participado en pequeños robos sólo por experimentar qué se siente.

12. He participado en robos.

15. Es fácil tomar cosas ajenas porque las personas son descuidadas con sus objetos.

21. Es divertido hacer ruido y alboroto en un lugar cuando todo está en silencio.

22. Cuando estoy aburrido en clase, inicio algún tipo de movimiento para divertirme.

23. Siento que a veces no puedo controlar mi impulso de hacer alguna travesura.

24. Es divertido observar cuando los compañeros se pelean.

No. de ítems (en negrilla saturaciones mayores a .30)

A Método de extracción: Componentes principales. Método de rotación: Oblimin. La rotación conversión en 11 iteraciones. Componentes: C1: Grafiti, C2: Abandono escolar, C3: Conducta oposicionista desafiante, C4: Pleitos, C5: Robos y C6: Travesuras.

Los componentes están correlacionados entre sí, salvo el tercero (Conducta oposicionista desafiante) con el segundo (Abandono escolar) y quinto (Robo). El que tiene las correlaciones más altas es el de Grafiti, seguido del sexto de Travesuras (véase tabla 4).

\begin{tabular}{|c|c|c|c|c|c|}
\hline 06 & -.80 & -.04 & .09 & -.07 & -.02 \\
\hline .02 & -.78 & -.12 & .14 & -.09 & -.01 \\
\hline 11 & -.66 & .17 & .04 & .02 & .00 \\
\hline .11 & -.63 & -.08 & -.03 & .02 & -.12 \\
\hline-.01 & -.62 & .09 & -.03 & -.31 & .09 \\
\hline .01 & -.57 & -.13 & .10 & -.13 & -.16 \\
\hline 05 & -.00 & .86 & .09 & -.03 & -.03 \\
\hline .07 & .02 & .76 & .02 & -.15 & -.07 \\
\hline .21 & .09 & .67 & .03 & .04 & -.08 \\
\hline-.02 & .05 & .06 & .83 & -.04 & .04 \\
\hline-.04 & -.11 & .12 & .80 & .15 & .06 \\
\hline .07 & .04 & -.02 & .73 & -.05 & -.00 \\
\hline .01 & -.14 & -.08 & .68 & .07 & -.10 \\
\hline-.07 & -.01 & .06 & -.10 & -.84 & -.09 \\
\hline .04 & .01 & .04 & .05 & -.81 & -.00 \\
\hline .09 & -.23 & -.01 & -.07 & -.67 & .06 \\
\hline-.03 & -.08 & .03 & .03 & -.61 & -.00 \\
\hline .00 & -.13 & -.01 & -.08 & .11 & -.82 \\
\hline .00 & .00 & .10 & .02 & -.05 & -80 \\
\hline-.06 & .02 & .11 & .11 & -.12 & -.68 \\
\hline .04 & -.07 & .04 & .30 & -.26 & -31 \\
\hline 10 & 6 & 3 & 4 & 4 & 4 \\
\hline 81 & .81 & .76 & .78 & .75 & .72 \\
\hline
\end{tabular}
C1: Grafi, C2: Abandono escolar, C3: Conducta oposicionista desaflante, C4:Pleitos, C5: Robos y

Tabla 4

Correlaciones entre los componentes

\begin{tabular}{ccccccc}
\hline Componentes & C1 & C2 & C3 & C4 & C5 & C6 \\
\hline C1 & 1 & & & & & \\
C2 & $-.19^{\star *}$ & 1 & & & & \\
C3 & $.14^{\star}$ & -.03 & 1 & & & \\
C4 & $.33^{\star *}$ & $-.17^{\star *}$ & $.15^{\star}$ & 1 & & \\
C5 & $-.18^{\star *}$ & $.26^{\star *}$ & -.04 & $-.20^{\star *}$ & 1 & \\
C6 & $-.24^{\star *}$ & $.14^{*}$ & $-.16^{\star}$ & $-.21^{\star *}$ & $.24^{* *}$ & 1 \\
\hline
\end{tabular}

$N=245 .{ }^{*} p<.05,{ }^{* *} p<.01$. Componentes: C1: Grafiti, C2: Abandono escolar, C3: Conducta oposicionista desafiante, C4: Pleitos, C5: Robos y C6: Travesuras. 
Se opta por reducir el número de ítems del componente de grafiti para homogeneizarlo con los demás y quedarnos con 27 ítems que dan nombre a las escala y es un objetivo del estudio. Los seis ítems más consistentes y que mejor definen el factor son: 28, 30, 32, 33, 34 y 35 (véase tabla 5). La consistencia interna de estos seis ítems es alta $(\alpha=.80)$.

Tabla 5

Saturación y consistencia de los ítems de componente de grafiti

\begin{tabular}{lccc}
\hline Ítems & \multicolumn{1}{c}{$\alpha_{c}$} & $\alpha_{c}$ & .43 \\
\hline 25. Alguna vez he participado en grafiti con mis amigos. & .43 & .40 \\
26. Me emociona subir a edificios muy altos para grafitear. & .51 & .46 & .80 \\
27. El grafiti es un arte que todos los jóvenes deben expresar. & .40 & .40 & .80 \\
28. Entre mayor riesgo se presente cuando grafiteas, la emoción aumenta. & .57 & .53 & .79 \\
30. Cuando grafiteas, por lo general, buscas espacios públicos. & .71 & .61 & .79 \\
31. Te irrita que grafiteen encima de alguna creación tuya. & .46 & .40 & .81 \\
32. Te sientes más confiado cuando grafiteas en grupo que cuando estás solo. & .76 & .61 & .78 \\
33. El tener permiso de las autoridades para grafitear hace que se pierda la emoción. & .62 & .44 & .79 \\
34. Me gusta que reconozcan mi firma en grafiti. & .61 & .56 & .78 \\
35. Me gustan las bardas recién pintadas para marcar mi firma (grafiti). & .69 & .63 & .78
\end{tabular}

$I$ = carga factorial en la solución de seis factores con 31 ítems, c = cálculo corregido con la eliminación del ítem en la correlación con la escala $\left(r_{c}\right)$ y en la alfa de Cronbach $\left(\alpha_{c}\right)$.

Al factorizar los 27 ítems por el criterio de Kaiser se definen seis componentes que explican el $59.97 \%$ de la varianza total. Se reproducen los seis componentes esperados en el mismo orden que las dos soluciones anteriores (véase tabla 6). Nuevamente, todos los componentes están correlacionados, salvo el tercero (Conducta oposicionista desafiante) con el segundo (Abandono escolar) y quinto (Robo). El que tiene las correlaciones más altas sigue siendo el de grafiti, seguido del de travesuras (véase tabla 7 ).

Tabla 6

Matriz de patrones con seis factores y 27 items

\begin{tabular}{|c|c|c|c|c|c|c|}
\hline \multirow{2}{*}{ Ítems } & \multicolumn{6}{|c|}{ Componentes } \\
\hline & $\mathrm{C} 1$ & $\mathrm{C} 2$ & C3 & $\mathrm{C} 4$ & C5 & C6 \\
\hline 32. Te sientes más confiado cuando grafiteas en grupo que cuando estás solo. & .79 & .06 & -.07 & -.00 & .04 & -.09 \\
\hline $\begin{array}{l}\text { 35. Me gustan las bardas recién pintadas para marcar } \\
\text { mi firma (grafiti). }\end{array}$ & .72 & -.11 & .00 & .00 & -.15 & -.05 \\
\hline 30. Cuando grafiteas, por lo general, buscas espacios públicos. & .71 & -.07 & .27 & -.00 & -.03 & .10 \\
\hline 34. Me gusta que reconozcan mi firma en grafiti. & .64 & .20 & .06 & .23 & -.12 & .08 \\
\hline $\begin{array}{l}\text { 33. El tener permiso de las autoridades para grafitear } \\
\text { hace que se pierda la emoción. }\end{array}$ & .63 & -.07 & -.13 & .01 & .03 & .03 \\
\hline
\end{tabular}


28. Entre mayor riesgo se presente cuando grafiteas, la emoción aumenta.

7. La escuela no es para mí.

8. Quiero abandonar la escuela.

9. He pensado dejar la escuela.

6. Por más esfuerzo que hago por terminar la escuela creo que no lo lograré.

10. La escuela es una pérdida de tiempo.

11. De reprobar dos o tres asignaturas al final del semestre, será mejor dejar la escuela y buscar trabajo.

19. Cuando creo que los adultos no tienen la razón los desafío a que me demuestren lo contrario.

18. No me dejo de los adultos cuando siento que no tienen la razón.

20. Trato de desafiar a los profesores que han sido injustos conmigo.

1. Cuando me agreden respondo inmediatamente a golpes.

2. Frecuentemente he tenido que pelear para defenderme.

4. Cuando me ofenden respondo inmediatamente y

si es necesario hasta con golpes.

3. Me gusta participar en pleitos.

13. Alguna vez he robado sin que nadie se dé cuenta.

14. He participado en pequeños robos sólo por experimentar que se siente.

12. He participado en robos.

15. Es fácil tomar cosas ajenas porque las personas son descuidadas con sus objetos.

21. Es divertido hacer ruido y alboroto en un lugar cuando todo está en silencio.

22. Cuando estoy aburrido en clase, inicio algún tipo de movimiento para divertirme.

23. Siento que a veces no puedo controlar mi impulso de hace alguna travesura. $\quad \begin{array}{llllll}-.04 & .07 & .07 & .11 & -.15 & -.69\end{array}$

24. Es divertido observar cuando los compañeros se pelean.

No. de ítems (en negrilla saturaciones mayores a .30)

A

Método de extracción: Componentes principales. Método de rotación: Oblimin. La rotación conversión en 11 iteraciones. Componentes: C1: Grafiti, C2: Abandono escolar, C3: Conducta oposicionista desafiante, C4: Pleitos, C5: Robos y C6: Travesuras.

Tabla 7

Correlaciones entre los componentes

\begin{tabular}{ccccccc}
\hline Componentes & $\mathrm{C} 1$ & $\mathrm{C} 2$ & $\mathrm{C} 3$ & $\mathrm{C} 4$ & $\mathrm{C} 5$ & $\mathrm{C} 6$ \\
\hline C1 & 1 & & & & & \\
C2 & $-.22^{\star \star}$ & 1 & & & & \\
C3 & $.15^{\star}$ & -.02 & 1 & & & \\
C4 & $.30^{\star \star}$ & $-.20^{\star \star}$ & $.20^{\star \star}$ & 1 & & \\
C5 & $-.15^{\star}$ & $.33^{\star *}$ & -.12 & $-.18^{\star \star}$ & 1 & \\
C6 & $-.18^{\star \star}$ & $.20^{\star \star}$ & $-.20^{\star *}$ & $-.20^{\star *}$ & $.24^{\star \star}$ & 1 \\
\hline
\end{tabular}

Componentes: C1: Grafiti, C2: Abandono escolar, C3: Conducta oposicionista desafiante, C4: Pleitos, C5: Robos y C6: Travesuras.

\begin{tabular}{|c|c|c|c|c|c|}
\hline .54 & -.17 & .07 & -.04 & .01 & -.19 \\
\hline .05 & -.84 & -.02 & .07 & -.03 & .01 \\
\hline-.05 & -.80 & -.10 & .13 & -.06 & .01 \\
\hline .12 & -.69 & -.03 & -.06 & .07 & -.08 \\
\hline .10 & -.69 & .17 & .03 & .05 & .02 \\
\hline-.10 & -.61 & .08 & -.01 & -.31 & .09 \\
\hline-.04 & -.60 & -.09 & .09 & -.10 & -.13 \\
\hline-.08 & -.04 & .89 & .06 & .03 & -.01 \\
\hline-.09 & -.00 & .78 & -.01 & -.10 & -.06 \\
\hline .18 & .04 & .70 & .01 & .08 & -.07 \\
\hline-.00 & .07 & .04 & .82 & -.06 & .02 \\
\hline-.04 & -.11 & .10 & .80 & .13 & .06 \\
\hline .09 & .02 & .00 & .71 & -.03 & -.00 \\
\hline .02 & -.12 & -.09 & .68 & .05 & -.11 \\
\hline-.05 & .02 & .03 & -.09 & -.85 & -.10 \\
\hline .093 & .06 & -.01 & .05 & -.82 & -.03 \\
\hline .09 & -.21 & -.04 & -.05 & -.68 & .06 \\
\hline .00 & -.06 & .01 & .03 & -.61 & -.00 \\
\hline .02 & -.10 & -.02 & -.08 & .11 & -.82 \\
\hline .04 & .02 & .09 & .01 & -.04 & -.80 \\
\hline-.04 & .07 & .07 & .11 & -.15 & -.69 \\
\hline .07 & -.04 & .03 & .29 & -.26 & -.33 \\
\hline 6 & 6 & 3 & 4 & 4 & 4 \\
\hline .80 & .81 & .76 & .78 & .75 & .72 \\
\hline
\end{tabular}


Se contrasta el modelo de seis factores correlacionados por análisis factorial confirmatorio. El modelo se define con todos los seis factores correlacionados, salvoeldeConductaoposicionista desafiante con los de Abandono escolar y Robo que son independientes. Se observa que todos sus parámetros son significativos, oscilando la varianza explicada de los ítems de $21 \%$ a $82 \%$, con una media $46.5 \%(D E=15.63 \%)$. Los índices de ajuste son de buenos $(\chi 2 / g l=1.50, P N C P=$ 0.63 y $R M S E A=.04)$ a adecuados $(G F I=.86$, $A G F I=.83$ y $F D=1.91$ ), aunque el modelo se rechaza por la prueba chi-cuadrado $(\chi 2(311)=$ 465.68, $p$ <.01) (véase figura 1).
También el modelo se contrasta por la modalidad multigrupo entre ambos sexos. Todos los parámetros del modelo sin restricciones son significativos en ambas muestras y los índices de ajuste son de buenos $(\chi 2 / \mathrm{gl}=1.31, P N C P=0.79$ y $R M S E A=.04)$ a adecuados $(F D=2.35, G F I=$ .85 y $A G F I=.80)$, aunque el modelo se rechaza por la prueba chi-cuadrado $(\chi 2(622)=813.66, p$ $<.01)$. Los valores de consistencia interna de los factores en hombres y mujeres son mayores a .70 , ligeramente más altos en hombres, salvo en el factor de Grafiti (véanse figuras 2 y 3 ).

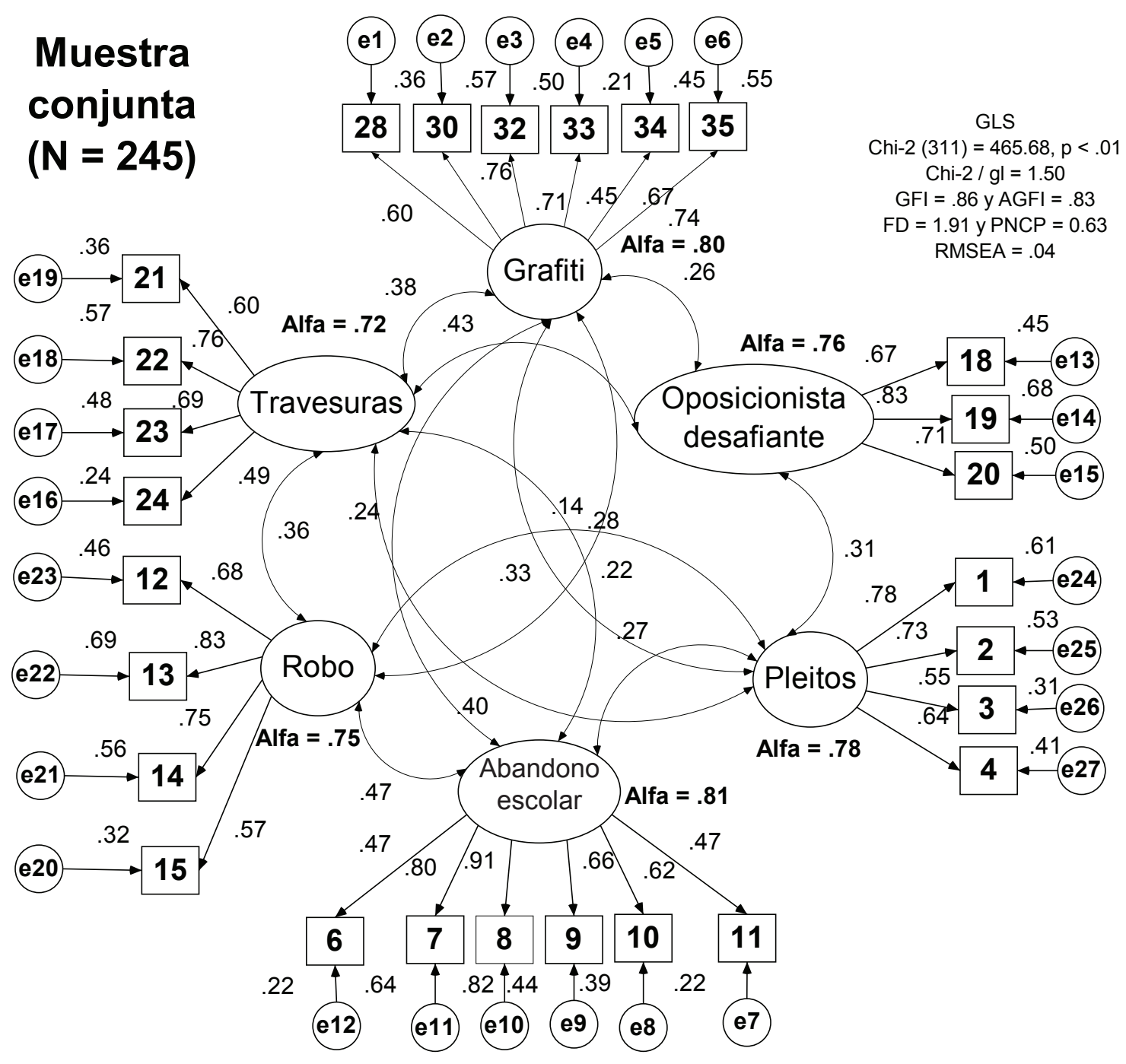

Figura 1. Modelo estandarizado sin restricciones en la muestra conjunta estimado por Mínimos Cuadrados Generalizados. 


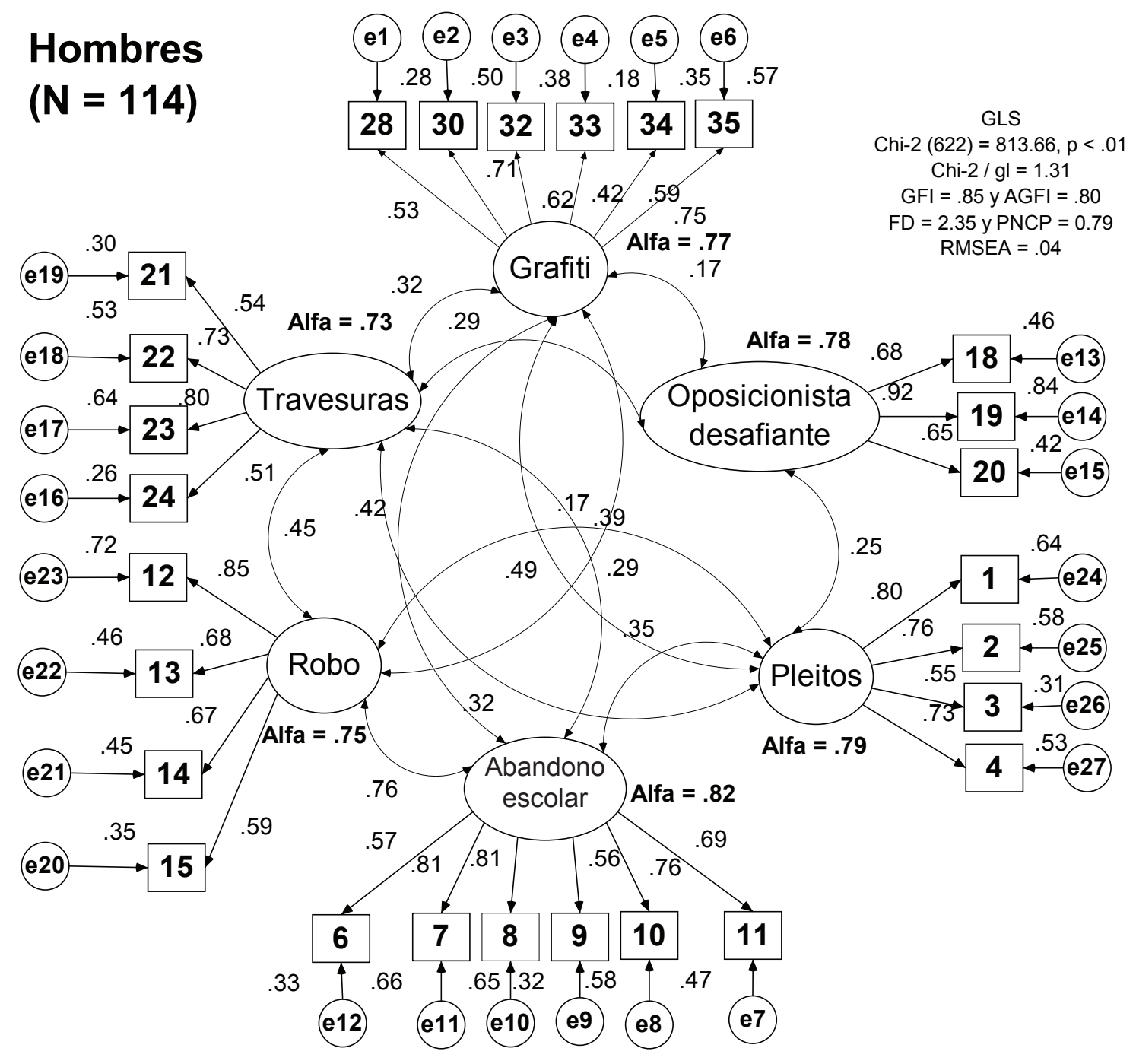

Figura 2. Modelo estandarizado sin restricciones en la muestra de hombres estimado por Mínimos Cuadrados Generalizados. 


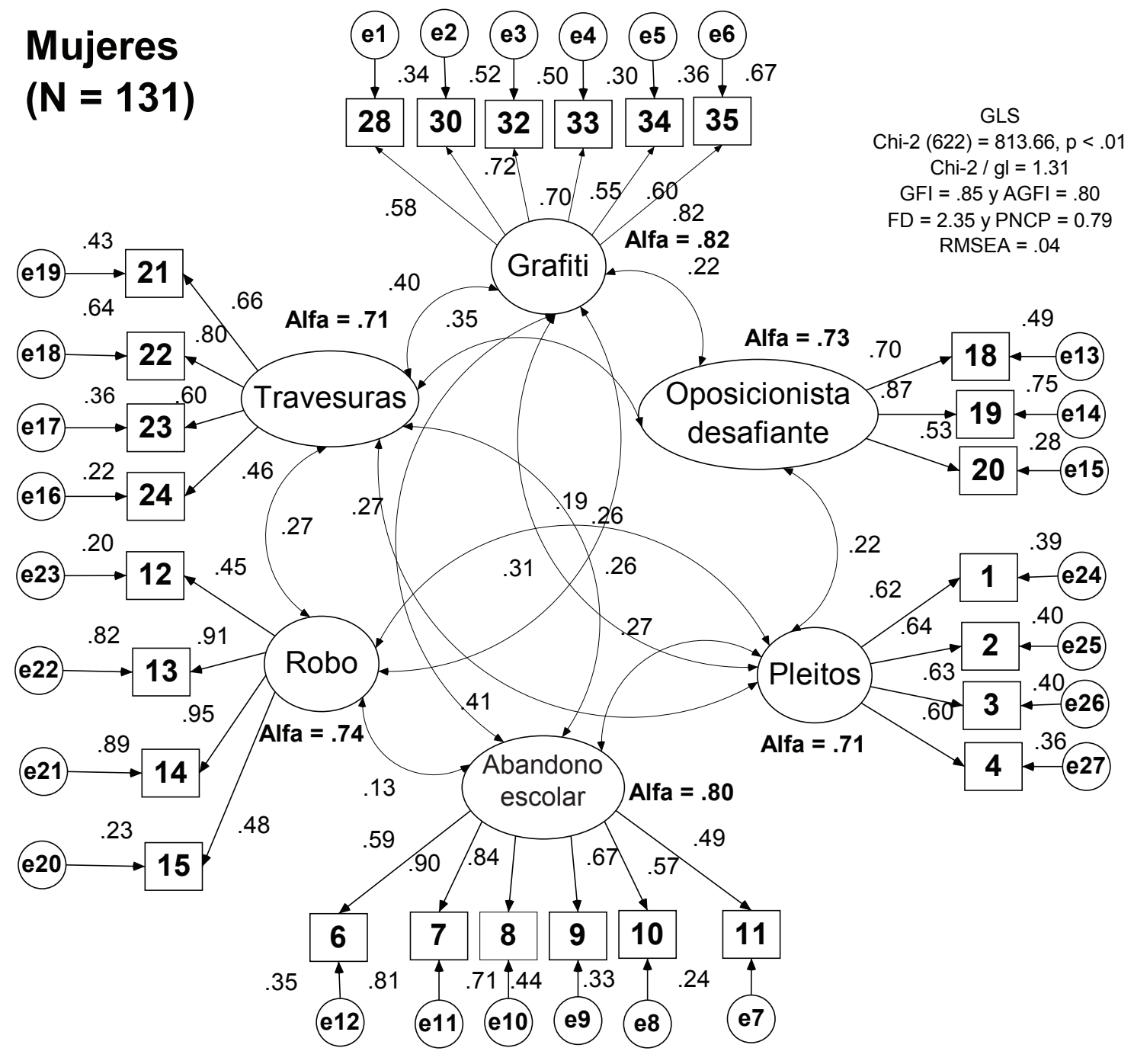

Figura 3. Modelo estandarizado sin restricciones en la muestra de mujeres estimado por Mínimos Cuadrados Generalizados. 
Tabla 8

Descriptivos de las distribuciones del puntaje total y los factores del ECODI27, segunda revisión y ajuste a una curva normal

\begin{tabular}{|c|c|c|c|c|c|c|c|c|}
\hline \multirow[b]{2}{*}{ Estadísticos } & & \multicolumn{7}{|c|}{ ECODI27-R2 } \\
\hline & & $\begin{array}{c}\text { Puntaje } \\
\text { total }\end{array}$ & Grafiti & $\begin{array}{c}\text { Abandono } \\
\text { escolar }\end{array}$ & Oposi-cionista & Pleitos & Robo & Trave-suras \\
\hline \multicolumn{2}{|l|}{$M$} & 116.88 & 26.74 & 28.00 & 11.13 & 15.53 & 19.33 & 16.16 \\
\hline \multicolumn{2}{|l|}{$D E$} & 11.92 & 4.12 & 3.03 & 2.96 & 3.59 & 1.53 & 3.26 \\
\hline \multicolumn{2}{|l|}{$S$} & -0.76 & -1.45 & -2.12 & -0.63 & -0.62 & -3.19 & -0.70 \\
\hline \multicolumn{2}{|l|}{$C$} & -0.02 & 1.51 & 5.27 & -0.13 & -0.32 & 12.42 & -0.33 \\
\hline \multirow{3}{*}{ Per-centiles } & 25 & 109 & 25 & 27 & 9 & 13 & 19 & 14 \\
\hline & 50 & 120 & 28 & 29 & 11 & 16 & 20 & 17 \\
\hline & 75 & 125 & 30 & 30 & 13 & 18 & 20 & 19 \\
\hline \multirow{2}{*}{ Norma-lidad } & $Z_{K S}$ & 1.82 & 3.35 & 3.98 & 1.88 & 1.94 & 6.38 & 2.02 \\
\hline & $p$ & .00 & .00 & .00 & .00 & .00 & .00 & .00 \\
\hline
\end{tabular}

$N=245 . E E$ de $S=0.16$ y $E E$ de $C=0.31$.

\section{Descripción de las distribuciones}

El puntaje total de la escala se define por la suma simple de 27 ítems, eliminando el ítem cinco de pleitos, 16 y 17 de Robo, 25, $26,27,29$ y 31 de grafiti. La distribución del puntaje total de media $116.88(D E=11.92)$ es asimétrica negativa $(S=-0.76, E E=.16)$, esto es, se concentra en puntuaciones por encima de la media, no ajustándose a una curva normal $\left(Z_{K-S}=1.82, p<.01\right)$. La mediana corresponde a 120 y las puntuaciones varían de 82 a 135 (véase figura 4). Igualmente ocurre con las distribuciones de los factores, las cuales son asimétricas negativas y no se ajustan a una curva normal (véase tabla 8).
Se divide la puntuación de cada factor por su número de ítems para lograr un rango homogéneo de 1 a 5, como el que corresponde a los ítems, para poder interpretar las medias y comparar las mismas. Por la prueba de Friedman hay diferencia significativa entre los seis factores $(\chi 2(5, N=245)=455.59, p$ $<.01)$. Las medias más bajas aparecen en conducta oposicionista desafiante $(M=3.71)$, pleitos $(M=3.88)$ y travesuras $(M=4.04)$, que corresponden a una respuesta de bastante en desacuerdo (4). Las más altas aparecen en robo $(M=4.83)$, Abandono escolar $(M=4.67)$, que corresponden a una respuesta de totalmente en desacuerdo (5). El factor de Grafiti $(M=4.46)$ se ubicaría en una posición intermedia entre ambos grupos (véanse tabla 9 y figura 5).

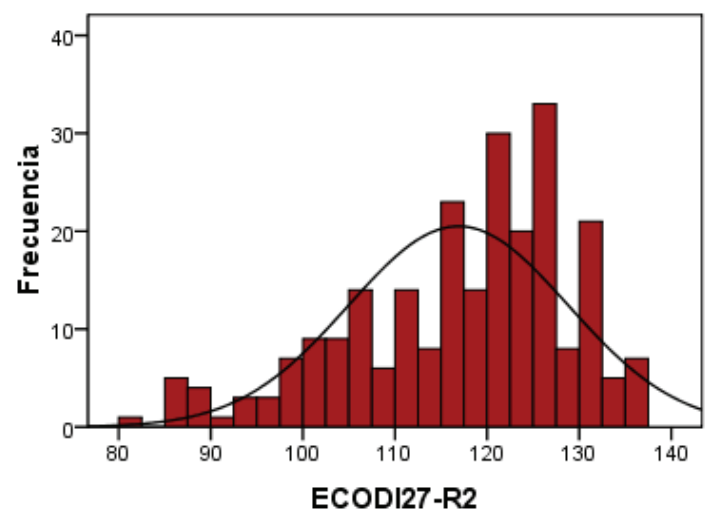

$\begin{aligned} \text { Mean } & =116.88 \\ \text { Std. Dev } & =11.92\end{aligned}$ Std. Dev. $=11.92$
$N=245$

Figura 4. Histograma del puntaje total del ECODI-27-R2. 
Tabla 9

Contraste de tendencia central por la prueba de Friedman

\begin{tabular}{cccccccccc}
\hline Factores $^{*}$ & \multicolumn{4}{c}{ Descriptivos } & \multicolumn{4}{c}{ Friedman } \\
\cline { 2 - 9 } & $N$ & $M$ & $D E$ & Min & Max & $R M$ & $\chi 2$ & $g l$ & $p$ \\
\hline Grafiti & 245 & 4.46 & 0.69 & 2.00 & 5 & 3.90 & 455.59 & 5 & .00 \\
Abandono escolar & 245 & 4.67 & 0.50 & 2.00 & 5 & 4.35 & & \\
Oposicionista & 245 & 3.71 & 0.99 & 1.00 & 5 & 2.39 & & \\
Pleitos & 245 & 3.88 & 0.90 & 1.25 & 5 & 2.57 & & \\
Robo & 245 & 4.83 & 0.38 & 2.25 & 5 & 4.99 & & \\
Travesuras & 245 & 4.04 & 0.82 & 1.75 & 5 & 2.80 &
\end{tabular}

* Rango homogeneizado al de los ítems de 1 a 5.

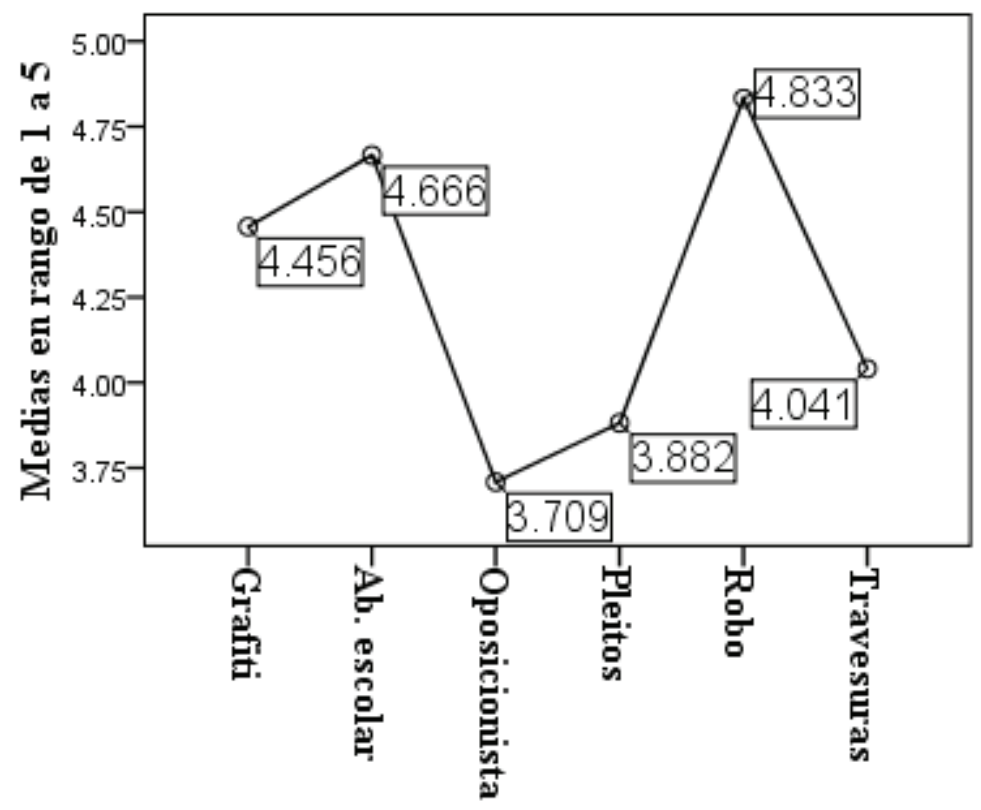

Figura 5. Medias en un rango homogeneizado de los seis factores. 
Tabla 10

Diferencia de tendencia central por sexos

\begin{tabular}{|c|c|c|c|c|c|c|c|c|}
\hline \multirow{2}{*}{ ECODI27-R2 } & \multirow{2}{*}{ Sexo } & \multicolumn{3}{|c|}{ Descriptivos } & \multicolumn{4}{|c|}{ Mann-Whitney } \\
\hline & & $N$ & $M$ & $D E$ & $R M$ & $U$ & $Z$ & $p$ \\
\hline \multirow{2}{*}{$\begin{array}{c}\text { Puntaje } \\
\text { total }\end{array}$} & $\mathrm{H}$ & 114 & 113.32 & 12.48 & 101.34 & 4997.5 & -4.47 & .00 \\
\hline & $M$ & 131 & 119.98 & 10.52 & 141.85 & & & \\
\hline \multirow{2}{*}{ Grafiti } & $\mathrm{H}$ & 114 & 25.96 & 4.35 & 108.13 & 5772 & -3.17 & .00 \\
\hline & $M$ & 131 & 27.41 & 3.80 & 135.94 & & & \\
\hline \multirow{2}{*}{$\begin{array}{c}\text { Abandono } \\
\text { escolar }\end{array}$} & $\mathrm{H}$ & 114 & 27.50 & 3.44 & 113.25 & 6355.5 & -2.14 & .03 \\
\hline & $M$ & 131 & 28.43 & 2.56 & 131.48 & & & \\
\hline \multirow{2}{*}{$\begin{array}{l}\text { Oposicionista } \\
\text { desafiante }\end{array}$} & $\mathrm{H}$ & 114 & 10.55 & 3.10 & 109.72 & 5953 & -2.75 & .01 \\
\hline & $M$ & 131 & 11.63 & 2.76 & 134.56 & & & \\
\hline \multirow{2}{*}{ Pleitos } & $\mathrm{H}$ & 114 & 14.36 & 3.79 & 100.70 & 4925 & -4.62 & .00 \\
\hline & $M$ & 131 & 16.54 & 3.08 & 142.40 & & & \\
\hline \multirow{2}{*}{ Robo } & $\mathrm{H}$ & 114 & 19.07 & 1.76 & 111.67 & 6175 & -3.03 & .00 \\
\hline & M & 131 & 19.56 & 1.27 & 132.86 & & & \\
\hline \multirow{2}{*}{ Travesuras } & $\mathrm{H}$ & 114 & 15.88 & 3.32 & 116.66 & 6744.5 & -1.32 & .19 \\
\hline & $M$ & 131 & 16.41 & 3.20 & 128.52 & & & \\
\hline
\end{tabular}

\section{Relación con las variables sociodemográficas}

Las mujeres tienen promedios más altos (menos rasgos disociales) en el puntaje total y cinco factores que los hombres. En el factor de travesuras los promedios son estadísticamente equivalentes (véase tabla 10).

La edad y el orden de nacimiento son independientes de puntaje total y los seis factores del ECODI27-R2. El número de hermanos tiene correlación negativa con el puntaje total y los factores de abandono escolar, robo, pleitos y travesuras. A menor número de hermanos, menor tendencia a la conducta disocial, abandonar los estudios, cometer robos, meterse en pleitos y hacer travesuras (véase tabla 11).
Se crea una variable ordinal sumando las variables de las ocupaciones de ambos padres, dando valor 1 a trabajador no cualificado, 2 a trabajador especializado, 3 a comerciante y 4 a trabajador profesional en el caso de los padres, y dando valor 0 a ama de casa, 1 a trabajadora no cualificada, 2 a trabajadora técnica, 3 a comerciante y 4 a trabajadora profesional en el caso de las madres. La puntuación varía de 1 (padre trabajador manual y madre ama de casa) a 8 (ambos padres profesionistas). A esta variable se le denomina nivel de ingresos familiares (NIF). El puntaje total del ECODI27-R2 $(r=.16, p=.03)$ y los factores de Pleitos $(r=.20, p<.01)$ y Grafiti $(r=.18, p=.01)$ correlacionan directamente con el nivel de ingresos familiares. A mayor nivel de ingresos, mayor puntuación, esto es, menos rasgos disociales (véase tabla 11). 
Tabla 11

Correlaciones con edad, número de hermano y orden de nacimiento entre los hermanos

\begin{tabular}{|c|c|c|c|c|c|}
\hline ECODI27-R2 & & Edad & $\begin{array}{l}\text { Número de } \\
\text { hermanos }\end{array}$ & $\begin{array}{c}\text { Lugar de } \\
\text { nacimiento }\end{array}$ & $\begin{array}{l}\text { Ingresos } \\
\text { familiares }\end{array}$ \\
\hline \multirow{3}{*}{ Puntaje total } & $r_{s}$ & -.11 & -.23 & -.03 & .16 \\
\hline & $p$ & .10 & .00 & .69 & .03 \\
\hline & $n$ & 219 & 241 & 207 & 189 \\
\hline \multirow{3}{*}{ Grafiti } & $r_{s}$ & -.08 & -.09 & .06 & .18 \\
\hline & $p$ & .24 & .17 & .37 & .01 \\
\hline & $n$ & 219 & 241 & 207 & 189 \\
\hline \multirow{4}{*}{ Abandono Escolar } & $r_{s}$ & -.12 & -.23 & -.07 & .12 \\
\hline & $\stackrel{s}{p}$ & .08 & .00 & .31 & .10 \\
\hline & $n$ & 219 & 241 & 207 & 189 \\
\hline & $r_{s}$ & -.02 & -.10 & -.07 & -.04 \\
\hline \multirow[t]{3}{*}{ Conducta oposicionista desafiante } & $p^{s}$ & .78 & .13 & .35 & .55 \\
\hline & $n$ & 219 & 241 & 207 & 189 \\
\hline & $r_{s}$ & -.07 & -.18 & -.06 & .20 \\
\hline \multirow[t]{3}{*}{ Pleitos } & $p^{s}$ & .29 & .00 & .38 & .00 \\
\hline & $n$ & 219 & 241 & 207 & 189 \\
\hline & $r_{s}$ & .01 & -.22 & -.03 & .14 \\
\hline \multirow[t]{3}{*}{ Robo } & $p^{s}$ & .87 & .00 & .69 & .06 \\
\hline & $n$ & 219 & 241 & 207 & 189 \\
\hline & $r_{s}$ & -.04 & -.13 & .03 & .06 \\
\hline \multirow[t]{2}{*}{ Travesuras } & $p^{s}$ & .56 & .04 & 62 & .43 \\
\hline & $n$ & 219 & 241 & 207 & 189 \\
\hline
\end{tabular}

En relación con la ocupación del padre (comerciante, trabajador manual, técnico o profesional), sólo hay diferencia significativa en el factor de pleitos entre los cuatro grupos. Los hijos de trabajadores técnicos y manuales tienen los promedios más bajos (más tendencia a los pleitos) y los hijos de profesionistas poseen el promedio más alto (menos tendencia). En relación con la ocupación de la madre (ama de casa, comerciante, trabajadora manual, técnica o profesional) sólo hay diferencia significativa en el factor de grafiti entre los cinco grupos. Los hijos de amas de casa tienen el promedio más bajo (más tendencia al grafiti callejero) y los de madres profesionistas el más alto (menos tendencia al grafiti callejero). En relación con el familiar con el que vive el adolescente (ambos padres, madre sola o padre solo), los valores de tendencia central son estadísticamente equivalentes entre los tres grupos en el puntaje total y los seis factores de ECODI27-R2 (véanse tabla 12 y 13).

Tabla 12

Valores de la prueba de contraste de tendencia central de Kruskal-Wallis

\begin{tabular}{|c|c|c|c|c|c|c|c|c|}
\hline Variables & $\mathrm{K}-\mathrm{W}$ & $\begin{array}{c}\text { Puntaje } \\
\text { Total }\end{array}$ & Grafiti & $\begin{array}{c}\text { Abandono } \\
\text { escolar }\end{array}$ & $\begin{array}{l}\text { Oposicio- } \\
\text { nista }\end{array}$ & Pleitos & Robo & Travesuras \\
\hline \multirow{3}{*}{$\begin{array}{c}\text { Ocupación } \\
\text { del } \\
\text { padre }\end{array}$} & $\chi^{2}$ & 4.45 & 3.91 & 4.63 & 4.94 & 9.21 & 5.27 & 1.71 \\
\hline & $d f$ & 3 & 3 & 3 & 3 & 3 & 3 & 3 \\
\hline & $\mathrm{p}$ & .22 & .27 & .20 & .18 & .03 & .15 & .63 \\
\hline \multirow{3}{*}{$\begin{array}{c}\text { Ocupación } \\
\text { de la } \\
\text { madre }\end{array}$} & $\chi^{2}$ & 7.15 & 10.40 & 3.18 & 0.46 & 8.43 & 4.85 & 4.25 \\
\hline & df & 4 & 4 & 4 & 4 & 4 & 4 & 4 \\
\hline & $p$ & .13 & .03 & .53 & .98 & .08 & .30 & .37 \\
\hline \multirow{3}{*}{$\begin{array}{l}\text { Con quien } \\
\text { vive }\end{array}$} & $\chi^{2}$ & 0.22 & 1.59 & 0.61 & 1.02 & 0.32 & 2.13 & 0.31 \\
\hline & $\mathrm{df}$ & 2 & 2 & 2 & 2 & 2 & 2 & 2 \\
\hline & $\mathrm{p}$ & .89 & .45 & .73 & .60 & .85 & .34 & .85 \\
\hline
\end{tabular}


Tabla 13

Diferencia de tendencia central en el factor de Pleitos por grupos de Ocupación del Padre y en el factor de Grafiti por grupos de Ocupación de la Madre

\begin{tabular}{|c|c|c|c|c|c|c|c|c|}
\hline \multirow{2}{*}{ Ocupación } & \multirow{2}{*}{ Categorías } & \multicolumn{3}{|c|}{ Descriptivos } & \multicolumn{4}{|c|}{$\mathrm{K}-\mathrm{W}$} \\
\hline & & $N$ & $M$ & $D E$ & $R M$ & $\chi^{2}$ & $g l$ & $p$ \\
\hline \multirow{7}{*}{$\begin{array}{l}\text { Del } \\
\text { padre }\end{array}$} & & \multicolumn{7}{|c|}{ Pleitos } \\
\hline & Trabajador no cualificado & 115 & 15.35 & 3.57 & 93.79 & 9.21 & 3 & .03 \\
\hline & Trabajador especializado & 22 & 14.64 & 3.12 & 79.00 & \multirow{10}{*}{10.40} & \multirow{10}{*}{4} & \multirow{10}{*}{.03} \\
\hline & Comerciante & 34 & 16.03 & 3.57 & 105.76 & & & \\
\hline & Trabajador profesional & 24 & 17.25 & 2.66 & 124.58 & & & \\
\hline & \multirow[t]{2}{*}{ Total } & 195 & 15.62 & 3.47 & & & & \\
\hline & & \multicolumn{7}{|c|}{ Grafiti } \\
\hline \multirow{6}{*}{$\begin{array}{c}\text { De la } \\
\text { madre }\end{array}$} & Ama de casa & 155 & 26.29 & 4.31 & 109.56 & & & \\
\hline & Trabajadora no cualificada & 36 & 27.14 & 4.13 & 126.35 & & & \\
\hline & Trabajadora técnica & 19 & 27.16 & 3.40 & 121.95 & & & \\
\hline & Comerciante & 7 & 27.43 & 4.68 & 134.00 & & & \\
\hline & Trabajadora profesional & 17 & 29.18 & 1.29 & \multirow[t]{2}{*}{159.38} & & & \\
\hline & Total & 234 & 26.74 & 4.13 & & & & \\
\hline
\end{tabular}

\section{Discusión}

Conforme con el objetivo del estudio se logra obtener la estructura de seis factores correlacionados con 27 ítems (contando de 3 a 6 indicadores cada factor) con un ajuste adecuado en términos generales y consistencia interna alta en los seis factores. Como se pretendía se fortalece el factor de grafiti que pierde el ítem más débil, como evidencian las versiones anteriores (Moral \& Pacheco, 2010a, en prensa), el ítem 27 "el grafiti es un arte que todos los jóvenes deben expresar", pero gana cuatro nuevos. Ahora resulta un factor con consistencia interna alta y uno de los más correlacionados con el resto de la escala. En esta nueva versión se acorta el factor de robo que pierde dos ítems, el de pleitos que pierde otro ítem y el de travesuras que también uno. Así, al incorporarse cuatro nuevos y perderse cuatro de la primera versión (Moral \& Pacheco, 2010a), se logra mantener los 27 ítems que dan nombre a la escala.

Desde el análisis de contenido aplicado a la grabación del grupo focal sobre el grafiti llevado a cabo con los estudiantes de primer semestre de diseño gráfico, se generó una categoría de modalidad de grafiti con tres subcategorías: violento, territorial y artístico. El grafiti violento se realiza como un acto de rebeldía, desafío a la autoridad y autoafirmación personal. El grafiti territorial es realizado por miembros de bandas con los símbolos que les son propios para identificar su territorio, comunicarse entre sí o provocar a otras bandas. En ambas modalidades no se pide permiso, se vive mucha emoción "pura adrenalina" y se evita a las autoridades. El grafiti artístico tiene una finalidad expresiva y decorativa, usualmente quienes lo practican piden permiso para pintar bardas, y tiene mayor calidad que las dos modalidades anteriores. No obstante, esta tipología no se consideró a la hora de seleccionar los nuevos ítems del factor de grafiti, ya que se pretendía que éste fuese unidimensional dentro del ECODI27, como finalmente se logra. Al analizar el contenido de los ítems retenidos, no hay indicios del grafiti artístico ni del territorial, pero sí claramente del violento, lo cual es consonante con el constructo de conducta disocial que pretende medir la escala.

En estudios previos, en los que adolescentes infractores y pandilleros eran parte sustantiva de la muestra (Moral \& Pacheco, 2010a, Moral, 
2010), el factor de grafiti presentó correlación moderada con robos y vandalismo. Esto se señalaba como un hecho no esperado y que podría reflejar aspectos culturales de los pandilleros en el noroeste de México y quizá se generalice a otros lugares y culturas, especialmente en el suroeste de Estados Unidos de América. Así, el grafiti aparece como una conducta disruptiva, muy asociada con el robo y vandalismo, y no como una conducta artística o de expresión cultural, como ya antes se indicó. En este estudio con sólo adolescentes escolarizados el factor de grafiti está teñido esencialmente de la modalidad de grafiti agresivo, y sigue correlacionando con el factor de robo.

Con esta nueva versión el factor de pleitos es más homogéneo en contenido y adecuado para un contexto escolar que es en el que se está estudiando la escala. Precisamente, en el espacio de convivencia de la escuela, no hay armas, existiendo un fuerte control al respecto, de ahí que el ítem que el factor pierde es el referente a portar armas para defenderse.

También debe señalarse que, al estar integrada la muestra por estudiantes, se va debilitando el factor de robo, debido a la baja frecuencia de esta conducta dentro de la población objeto de estudio. En el estudio original, en el que incluyó una muestra de menores delincuentes, aparte de otra de estudiantes, el factor de robo era el que incluía mayor número de ítems y poseía mayor consistencia (Moral \& Pacheco, 2010a, 2010b).

Como en estudios previos el factor de travesuras es el más relacionado con los demás, el único que muestra distribución normal y equivalencia entre ambos sexos, además su promedio es de los más bajos, lo cual indica que son conductas relativamente frecuentes y adaptativas entre estos adolescentes escolarizados. Contrario al factor de robo que tiene el promedio más alto y distribución con marcada asimetría hacia los valores altos o de desacuerdo con este tipo de conducta.
Como se esperaba en esta población de estudiantes la distribución del puntaje total y los factores, salvo el de travesuras, son asimétricas negativas. Esto refleja que los rasgos disociales son poco comunes frente rasgos de personalidad como la impulsividad (Ray, Poythress, Weir \& Rickelm, 2008). Por lo tanto, la escala debe estandarizarse por los percentiles en lugar de la media y la desviación estándar.

Aparte de reflejar un bajo nivel de rasgos disociales entre adolescentes escolarizados (Juárez et al., 2005), estas puntuaciones bajas también podrían deberse a un sesgo de respuesta relacionado con la falta de sinceridad o deseabilidad social. En el estudio original (Pacheco \& Moral, 2010) el puntaje total del ECODI27 presentó una correlación baja con deseabilidad social en la muestra de estudiantes ( $n=648, r=-.13, p<.01$ ), así como los factores de travesuras, conducta oposicionista desafiante y abandono escolar; y en la muestra de infractores sólo correlacionan los factores de conducta oposicionista desafiante y travesuras ( $r=-.18, p<.03$, en ambos). Este constructo se midió con la escala de Sinceridad del Inventario de Personalidad de Eysenck (EPI; Eysenck y Eysenck, 1990), la cual evalúa esencialmente el componente de manejo de la impresión (Paulhus, 2002). No obstante, la correlación del ECODI27 fue moderada con deseabilidad social, al medirse el constructo con el Inventario balanceado de deseabilidad social al responder (BIDR; Paulhus, 1998) tanto en una muestra de estudiantes de preparatoria (Moral \& Pacheco, en prensa) como en una muestra de adolescentes que viven en colonias con alto índice de delitos y pandillas (Moral \& Ortiz, 2011), especialmente con el factor de manejo de la impresión. Por lo tanto, el instrumento de medida que presenta cierto sesgo en relación con el manejo de la impresión que se evidencia con instrumentos confiables, es consonante con el constructo y se observa con otros instrumentos de medida (Echeburúa, Amor \& Corral, 2003; Rogers et al., 2002). 
Conforme a la expectativa (Garaigordobil, 2005; Zahn, Chirtcliff, Marceau, 2008) y como evidencia de validez los hombres reportan significativamente más rasgos de conducta disocial (menor promedio en el ECODI-27-R2) que las mujeres. Estas diferencias entre los sexos, en la literatura especializada, se vienen atribuyendo a los rasgos de impulsividad y agresividad diferenciales en relación con la adaptación a los roles socio-biológicos de caza y defensa territorial en el varón y crianza en la hembra (Bonilla \& Fernández, 2006); asimismo, a la socialización y control social que socavan y desincentivan los rasgos de agresividad, impulsividad y rebeldía en la mujer, pero no tanto en los varones, se pone de manifiesto especialmente en las guarderías (Kaplan, 2003).

La conducta antisocial disminuye en intensidad y gravedad con la edad (APA, 2000; Benjet at al., 2010). La persona al ir madurando y envejeciendo se vuelve más empática, controlada y responsable en comparación con su comportamiento en la adolescencia y la juventud. En parte se debe a la disminución con la edad de la impulsividad, agresividad y tendencia a la rebeldía (Hare, 2003; Millon, 2004). No obstante, por el rango limitado de la muestra (de 14 a 18 años), este efecto no es evidente (Eisenberg, 2005; Garaigordobil, 2005; Miller et al., 2010). Así los participantes se hallan en la adolescencia que constituye la etapa de la vida de mayor vitalidad y rebeldía (Bonilla \& Fernández, 2006; Herrero, Ordoñez, Salas \& Colom, 2002).

Un mayor número de hermanos sí correlaciona con mayores rasgos disociales, pero no así el orden de nacimiento. El mayor número de hermanos actúa a través de los menores recursos de la familia, menor control paterno, al trabajar ambos padres en largas jornadas y el ejemplo de los hermanos mayores si éstos se hallan metidos en pandillas o tienen amigos pandilleros (Silva, 2003). Además, este correlato es de los más constantes, junto al sexo y el barrio, en diversos estudios (Barak, 2009;
Garaigordobil, 2005). El orden de nacimiento no está claramente asociado con conducta disocial y varía de una investigación a otra, especialmente, en muestras de estudiantes, en las cuales el número de casos es bajo (Bègue \& Roché, 2005; Lalumière, et al., 2004).

Se esperaba que aquéllos que viven con ambos padres mostraran menos rasgos disociales que aquéllos que viven con sólo uno de los padres, lo que no se confirma. Si consideramos que el porcentaje de divorcios es bajo en México, en torno al 13\% y que el reporte de violencia es alto (Instituto Nacional de Estadística, Geografía e Informática, 2008), esto podría reflejar un nivel importante de conflicto dentro de las familias mexicanas integradas por ambos padres que se refleja en problemas de conducta en los hijos. Por lo tanto, la familia nuclear no constituye un factor protector frente a las familias monoparentales en las cuales usualmente están presentes los abuelos (Consejo Nacional de Población, 2010).

En la literatura especializada se atribuye la menor presencia de rasgos disociales entre hijos de profesionistas al mayor ingreso económico familiar y posibilidad de vivir en barrios residenciales en los cuales hay menor presencia o total ausencia de pandillas frente a los hijos de padres con trabajos no cualificados que residen en barrios populares con presencia importante de delincuencia y pandillas (Mobilli \& Rojas, 2006; Silva, 2003), como ocurre en la ciudades del norte de México (Cerda, 2009). Precisamente, al crear la variable de nivel de ingresos familiares a partir de las ocupaciones de ambos padres se confirma esta asociación.

En relación con las ocupaciones, se observa menos tendencia a los pleitos entre hijos de padres profesionistas y a practicar el grafiti entre hijos de madres profesionistas frente a padres con trabajos técnicos o no cualificados y amas de casa. Lo primero podría atribuirse a un aspecto de educación, modales y forma de resolver conflictos donde el padre es el modelo de identidad y conducta para los 
jóvenes. Lo segundo al ingreso familiar, ya que al parcializar el efecto de esta variable por análisis de covarianza la diferencia de medias deja de ser significativa $(F(1,189)=0.36, p=$ $.84)$. Precisamente en las familias donde hay amas de casa su valor en la variable de nivel de ingresos familiares desciende.

Como limitaciones del estudio debe señalarse el carácter no probabilístico de la muestra. Aunque su tamaño grande nos permite alcanzar potencia alta en las pruebas de contraste, toda generalización debe manejarse como una hipótesis aplicable a una población semejante, donde el participante promedio es un estudiante de preparatoria pública con 15 años de edad, que vive con ambos padres, pertenece a clase media-baja, su padre tiene un empleo como trabajador no cualificado, su madre es ama de casa y tiene dos hermanos. Debe señalarse que este participante promedio es bastante representativo de la población estudiada (Secretaría de Educación Pública del estado de Baja California, 2011). La naturaleza de los datos es de autoinforme. Con entrevistas de preguntas abiertas, escalas de observación, pruebas proyectivas o registros psicofisiológicos, los resultados podrían diferir y se requeriría una teoría de la conducta humana para su interpretación. Finalmente se carece de una medida de manejo de la impresión para controlar su sesgo en los contrastes.

En conclusión, la escala logra conservar 27 ítems a costa de perder cuatro e incorporar otros cuatros nuevos para el factor de grafiti. Este factor alcanza consistencia interna alta y es uno de los más correlacionados con los restantes. La escala también conserva sus seis factores correlacionados, todos ellos con valores de consistencia interna altos, distribuciones sesgadas hacia los valores altos (menores rasgos disociales), salvo Travesuras que presenta distribución normal, siendo el ajuste de este modelo estructural adecuado a los datos. Se reduce el factor de Robo, Pleitos y Travesuras, ajustándose más su contenido al ámbito escolar. Los hombres reportan significativamente más rasgos disociales, asimismo, los rasgos disociales correlacionan con mayor número de hermanos y menor ingreso familiar, lo que proporciona evidencias de validez. Resulta independiente del orden de nacimiento, como también se observa en otros estudios, cuando esta variable sociodemográfica está más asociada con desviaciones sexuales (Lalumière et al., 2005) y homosexualidad (Cantor, Blanchard, Paterson \& Bogaert, 2002). También es independiente de la edad, lo que se atribuye al rango reducido de edades dentro del periodo adolescente. Así se trata de una escala confiable y válida con mejoras con respecto a las dos versiones anteriores, y más adaptada al contexto escolar.

Se sugiere estudiar esta versión en relación con la deseabilidad social, como el inventario BIDR (Paulhus, 1998), para establecer alguna regla de corrección, y con criterios clínicos, como la Entrevista Clínica Estructurada para trastornos del Eje I (SCID-I; First, Spitzer, Gibbon \& Williams, 1997), para contrastar su validez criterial y el punto de corte de definición de caso; asimismo, establecer los baremos de la escala por medio de percentiles, empleando un muestreo probabilístico entre escolares de educación media superior y menores infractores. Una vez que se posea la regla de corrección en relación con la deseabilidad social, los baremos poblacionales y punto de corte para definir un caso, esta escala confiable y válida resultará de gran utilidad en el contexto clínico, escolar e incluso forense entre adolescentes mexicanos. Finalmente, se desea estimular el estudio del ECODI27 en otros países de habla hispana. 


\section{Referencias}

American Psychiatric Association. (2000). Diagnostic and statistical manual of mental disorders, 4th edition, text revision (DSM-IV-TR). Washington, DC: American Psychiatric Association.

American Psychological Association. (2002). Ethical principles of psychologists and code of conduct. American Psychologist, 57, 1060-1073.

Barak, G. (2009). Criminology: An integrated approach. Lanham, MD: Rowman and Littlefield Publisher.

Bègue, L., \& Roché, S. (2005). Birth order and youth delinquent behaviour testing the differential parental control hypothesis in a French representative sample. Psychology, Crime \& Law, 11, 73-85.

Benjet, C., Borges G., Medina, M.E., Blanco, J., Rojas, E., Fleiz, C., Méndez, E., Zambrano, J. \& Aguilar, S.A. (2009). La Encuesta de Salud Mental en Adolescentes de México. En J. Rodríguez, R. Kohn \& S.A. Aguilar (Eds.). Epidemiología de los trastornos mentales en América Latina y el Caribe (pp. 90-100). Washington, DC: PAHO.

Benjet, C., Borges, G., Medina, M.E., Méndez, E., Fleiz, C., Rojas, E. \& Cruz, C. (2009). Diferencias de sexo en la prevalencia y severidad de trastornos psiquiátricos en adolescentes de la Ciudad de México. Salud Mental, 32(2), 155-163.

Benjet, C., Borges, G. \& Medina, M.E. (2010). Chronic childhood adversity and onset of psychopathology during three life stages: childhood, adolescence and adulthood. Journal of Psychiatric Research, 44, 732-740.

Bonilla, J. \& Fernández, S. (2006). Neurobiología y Neuropsicología de la conducta antisocial. Psicología Clínica, Legal y Forense, $6,67-81$.

Cantor, J.M., Blanchard, R., Paterson, A.D. \& Bogaert, A.F. (2002). How many gay men owe their sexual orientation to fraternal birth order? Archives of Sexual Behavior, 31, 63-71.

Cava, M.J. \& Musitu, G. (2000). Perfil de los niños con problemas de integración social en el aula. Revista de Psicología Social, $15,319-333$.

Cerda, P. (2009). Violencia y Ciudad. Monterrey: Universidad Autónoma de Nuevo León.

Consejo Nacional de Población. (2010). Encuesta Nacional de Ingreso y Gasto de los Hogares. México, DF: CONAPO.

Cronbach, L.J. \& Shavelson, R.J. (2004). My current thoughts on coefficient alpha and successor procedures. Educational and Psychological Measurement 64, 391-418.

Diamond, G. \& Josephson A. (2005). Family-based treatment research: a 10-year update. Journal of American Academic Child Adolescent Psychiatry, 44, 872-887.

Echeburúa, E., Amor, P.J. \& Corral, P. (2003). Autoinformes y entrevistas en el ámbito de la psicología clínica forense: limitaciones y nuevas perspectivas. Análisis y Modificación de Conducta, 29, 503-522.
Eisenberg, N. (2005). Age changes in prosocial responding and moral reasoning in adolescence and early adulthood. Journal of Research on Adolescence, 15, 235-260.

Eysenck, H.J. \& Eysenck, S.B.G. (1990). EPI. Cuestionario de Personalidad. Madrid: TEA.

First, M.B., Spitzer, R.L., Gibbon, M. \& Williams, J.B.W. (1997). Structured clinical interview for DSM-IV axis I disordersclinician version (SCID-CV). Washington, DC: American Psychiatric Association Press.

Garaigordobil, M. (2005). Conducta Antisocial durante la adolescencia: Correlatos socioemocionales, predictores y diferencias de género. Psicología Conductual, 13, 197-215.

Juárez, F., Villatoro, J., Gutiérrez, M.L., Fleiz, C. \& Medina, M.E. (2005). Tendencias de la conducta antisocial en estudiantes del Distrito Federal: Mediciones 1997-2003. Salud Mental, 28(3), 60-68.

Hare, R.D. (2003). Hare psychopathy checklist-revised (PCL-R). Technical manual. North Tonawanda, NY: Multi-Health Systems.

Herrero, O., Ordoñez, F., Salas, A. \& Colom, R. (2002). Adolescencia y comportamiento antisocial, Psicothema 14, 340-343.

Instituto Nacional de Estadística, Geografía e Informática. (2008). Encuesta Nacional sobre la dinámica de las relaciones en los hogares. Aguascalientes: INEGI.

Kaplan, H. (2003). Social psychological perspectives on deviance. En J. Delamater (Ed.). Handbook of social psychology (pp. 451-478). New York: Kluwer Academic/Plenum Publishers.

Kline, R. B. (2010). Principles and practice of structural equation modeling (3rd ed.). New York: Guilford Press.

Lalumière, L.M., Harris, G.T., Quinsey, V.L. \& Rice, M.E. (2004). Sexual deviance and number of older brothers among sexual offenders. Sexual Abuse: A Journal of Research and Treatment, 10, 5-15.

Martins-da Cruz, D. \& Costa, M.T. (2008). Graffiti and graffiting what kind of communication is that? LINHAS, 9(2), 95-112.

López, C., Castro, M., Alcántara, M., Fernández V. \& López, J.A. (2009). Prevalencia y características de los síntomas externalizantes en la infancia. Diferencias de género. Psicothema, 21, 353-358.

Miller, S., Malone, P.S. \& Dodge, K.A. (2010). Developmental trajectories of boys' and girls' delinquency: sex differences and links to later adolescent outcomes. Journal of Abnormal Child Psychology, 38, 1021-1032.

Millon, T. (2004). Personality disorders in modern life. London: John Wiley and Sons.

Mobilli, A. \& Rojas, C. (2006). Aproximaciones al adolescente con trastorno de conducta disocial. Investigación en Salud, 8(2), 121-128.

Moral, J. (2006). Análisis factorial confirmatorio. En R. Landero \& M.T. González (Eds.), Estadística con SPSS y metodología de la investigación (pp. 445-528). México, DF: Trillas. 
Moral, J. (2010). Validación de la Escala de Conducta Disocial (ECODI27) en una muestra probabilística de adolescentes mexicanos. Perspectivas sociales, 12(2), 41-68.

Moral, J. \& Ortiz, H. (2011). Modelos predictivos por género de conducta disocial en dos colonias populares. Salud Mental, 34(3), 227-235.

Moral, J. \& Pacheco, M.E. (2010a). Propiedades psicométricas de una Escala de Conducta Disocial en adolescentes del noreste de México. Revista Electrónica de Psicología Iztacala, 14(1), 199-221.

Moral, J. \& Pacheco, M.E. (2010b). Consistencia interna y validación de la estructura factorial de la Escala de Conducta Disocial (ECODI27) en tres muestras distintas. Anuario de Psicología Jurídica, 20, 15-29.

Moral, J. \& Pacheco, M.E. (en prensa). Revisión de la Escala de Conducta Disocial de 27 Reactivos. Revista Mexicana de Orientación Educativa (REMO), 23.

Musitu, G. (2001). Familia y adolescencia: un modelo de análisis e intervención psicosocial. Madrid: Síntesis.

Pacheco, M.E. \& Moral, J. (2010). Distribución, punto de corte y validez de la Escala de Conducta Disocial (ECODI27). Revista Mexicana de Orientación Educativa (REMO), 7(18), 7-16.

Paulhus, D.L. (1998). Manual for balanced inventory of desirable responding: Version 7 (BIDR-7). Multi-Health Systems, Toronto, ON.

Pauhlus, D. L. (2002). Socially desirable responding: The evolution of a construct. En H. Brau, D. Jackson \& D.E. Wiley (Ed.). The role of constructs in psychological and educational measurement (pp.46-69). Mahwah, NJ: Lawrence Erlbaum.

Ray, J.V., Poythress, N.G., Weir, J.M. \& Rickelm, A. (2008). Relationships between psychopathy and impulsivity in the domain of self-reported personality features. Personality and Individual Differences, 46(2), 83-87.

Rogers, R., Vitacco, M.J., Jackson, R.L., Martin, M., Collins, M. \& Sewell, K.W. (2002). Faking psychopathy? An examination of response styles with antisocial youth. Journal of Personality Assessment, 78, 31-46.

Santrock, J.W. (2008). A topical approach to life-span development. En Moral development, values, and religion: Antisocial Behavior (pp. 491-495). Boston, Massachusetts: McGraw-Hill.

Secretaría de Educación Pública del estado de Baja California. (2011). Estadísticas por niveles educativos. Fin 2009-2010. Mexicali: Secretaría de Educación Pública.

Silva, A. (2003). Conducta antisocial: un enfoque psicológico. México: Pax.

Sociedad Mexicana de Psicología. (2007). Código ético del psicólogo (4ª edición). México, DF: Trillas.

Yogan, L.J. \& Johson, L.M. (2006). Gender differences in jail art and graffiti. The South Shore Journal, 1, 31-52.

Zahn, C., Chirtcliff, E.A. \& Marceau, K. (2008). Disorders of childhood and adolescence: Gender and psychopathology. Annual Review of Clinical Pscyhology, 4, 275-303. 


\section{Anexo
Escala de Conducta Disocial (ECODI)}

Indique en qué grado está conforme con cada una de las siguientes afirmaciones que describen su comportamiento habitual.

\begin{tabular}{|c|c|c|c|c|}
\hline TA & BA & nAnD & BD & TB \\
\hline Totalmente de acuerdo & $\begin{array}{c}\text { Bastante de } \\
\text { acuerdo }\end{array}$ & $\begin{array}{c}\text { Ni de acuerdo ni en } \\
\text { desacuerdo }\end{array}$ & $\begin{array}{c}\text { Bastante en } \\
\text { desacuerdo }\end{array}$ & Totalmente en desacuerdo \\
\hline
\end{tabular}

\section{Afirmaciones que describen su conducta habitual}

1. Cuando me agreden respondo inmediatamente a golpes.

2. Frecuentemente he tenido que pelear para defenderme.

3. Me gusta participar en pleitos.

4. Cuando me ofenden respondo inmediatamente y si es necesario hasta con golpes.

5. Es necesario andar armado porque estás expuesto a que en cualquier momento te puedan agredir.

6. Por más esfuerzo que hago por terminar la escuela creo que no lo lograré.

7. La escuela no es para mí.

8. Quiero abandonar la escuela.

9. He pensado dejar la escuela.

10. La escuela es una pérdida de tiempo.

11. De reprobar dos o tres asignaturas al final del semestre, será mejor dejar la escuela y buscar trabajo.

12. He participado en robos.

13. Alguna vez he robado sin que nadie se dé cuenta.

14. He participado en pequeños robos sólo por experimentar qué se siente.

15. Es fácil tomar cosas ajenas porque las personas son descuidadas con sus objetos.

16. Me gusta planear robos.

17. He estado involucrado en actividades que dañan la propiedad ajena como: autos, casas, edificios públicos y objetos.

18. No me dejo de los adultos cuando siento que no tienen la razón.

19. Cuando creo que los adultos no tienen la razón los desafío a que me demuestren lo contrario.

20. Trato de desafiar a los profesores que han sido injustos conmigo.

\section{Conformidad}

TA BA $\mathrm{nAnD}$ BD TD 


\section{Afirmaciones que describen su conducta habitual}

\section{Conformidad}

TA BA nAnD BD TD

21. Es divertido hacer ruido y alboroto en un lugar cuando todo está en silencio.

22. Cuando estoy aburrido en clase, inicio algún tipo de movimiento para divertirme.

23. Siento que a veces no puedo controlar mi impulso de hace alguna travesura.

24. Es divertido observar cuando los compañeros se pelean.

25. Alguna vez he participado en grafiti con mis amigos.

26. Me emociona subir a edificios muy altos para grafitear.

27. El grafiti es un arte que todos los jóvenes deben expresar.

28. Entre mayor riesgo se presente cuando grafiteas, la emoción aumenta.

29. El grafiti debe ser reconocido como una actividad artística.

30. Cuando grafiteas, por lo general, buscas espacios públicos.

31. Te irrita que grafiteen encima de alguna creación tuya.

32. Te sientes más confiado cuando grafiteas en grupo que cuando estás solo.

33. El tener permiso de las autoridades para grafitear hace que se pierda la emoción.

34. Me gusta que reconozcan mi firma en grafiti.

35. Me gustan las bardas recién pintadas para marcar mi firma (grafiti). 